\title{
Elucidating the viral and host factors enabling the cross-species transmission of primate lentiviruses from simians to humans
}

\section{Short title: SIV to HIV cross species transmission}

Denis M. Tebit ${ }^{1,2,3}$, Gabrielle Nickel ${ }^{1}$, Richard Gibson ${ }^{1,4}$, Crystal Carpenter ${ }^{1}$, Myriam Rodriguez ${ }^{1}$, Nicolas J. Hathaway ${ }^{5}$, Katie Bain ${ }^{4}$, Angel L. Reyes-Rodriguez ${ }^{6}$, Jennifer Bonogo ${ }^{6}$, David Canaday $^{1}$, David McDonald ${ }^{6}$, Jeffrey A. Bailey ${ }^{5,7}$, Eric J. Arts ${ }^{1,4}$

${ }^{1}$ Division of Infectious Diseases, Department of Medicine, Case Western Reserve University, Cleveland, Ohio

${ }^{2}$ Global Biomed Scientific, LLC, P.O. Box 2368, Forest, Virginia

${ }^{3}$ Department of Microbiology, University of Venda, Thohoyandou, Limpopo Province, South Africa

${ }^{4}$ Department of Microbiology and Immunology, Western University, Ontario, Canada

${ }^{5}$ Program in Bioinformatics and Integrative Biology, University of Massachusetts, Worcester, Massachusetts

${ }^{6}$ Department of Molecular Biology and Microbiology, Case Western Reserve University School of Medicine, Cleveland, Ohio

${ }^{7}$ Department of Pathology and Laboratory Medicine, Warren Alpert Medical School, Brown University, Providence, Rhode Island 


\section{ABSTRACT}

The HIV-1 epidemic originated from a cross-species transmission of a primate lentivirus from chimpanzees to humans near the turn of the $18^{\text {th }}$ century. Simian immunodeficiency viruses have been jumping between old world monkeys in West/Central Africa for thousands of years. So why did HIV-1 only emerge in the past century? This study examined the replicative fitness, transmission, restriction, and cytopathogenicity of 26 primate lentiviruses. Pairwise competitions of these primate lentiviruses revealed that SIVcpz had the highest replicative fitness in human or chimpanzee peripheral blood mononuclear cells, even higher fitness than HIV-1 group M strains responsible for 37 million infections worldwide. In contrast the "HIV-2 lineage" (SIVsmm, SIVmac, SIVagm, and HIV-2) had the lowest replicative fitness. SIVcpz strains were less inhibited by human restriction factors than the "HIV-2 lineage" strains, a restriction that was inversely correlated with replicative fitness. SIVcpz from the chimpanzee subspecies Pan troglodytes troglodytes $(P t t)$ was slightly more fit in human cells than the strains from Pt schweinfurthii $(P t s)$. However, unlike all other primate lentiviruses (including the HIV-2 lineage), SIVcpz was nonpathogenic in human tonsillar tissue and did not deplete CD4+ T-cells, consistent with the slow or nonpathogenic disease observed in chimpanzees. Despite the close phylogenetic relationship between SIVcpz_Ptt and HIV-1, this epidemic was either caused by cross species transmission of a rare, undiscovered SIVcpz strain of higher virulence or higher virulence differentially evolved among HIV-1 subtypes during the human epidemic. 


\section{Author summary}

Invasion of wild animal habitats by humans can have devastating consequences for the human population as evident by the HIV-1 and SARS-CoV-2 epidemics. With SARS-CoV-2, a recent zoonotic jump, likely from bats, will help to identify a coronavirus progenitor. In contrast, simian immunodeficiency virus (SIV) jumped into humans over 100 years ago from a possibly extinct sub-species of chimpanzees and/or extinct lineage of SIV. We examined replicative fitness and pathogenesis of 26 different primate lentiviruses in human and chimpanzee primary lymphoid cells from blood and within tonsils. SIV from a specific chimpanzee species and lowland gorillas were the most capable of infecting and replicating in human and chimp lymphoid cells but they did not result in the pathogenesis related to disease in humans. In contrast, SIV from other old world monkeys were pathogenic but could not replicate efficiently in human cells. We propose the main HIV-1 is derived from a distinct jump of a very rare SIV strain in chimps leading to AIDS pandemic. 


\section{INTRODUCTION}

Simian immunodeficiency viruses (SIV) are a collection of primate lentiviruses differing as much as $50 \%$ (in nucleotide diversity) and infecting a genetically diverse population of old world monkeys $(1,2)$. In contrast the distinction between "human" immunodeficiency virus type 1 (HIV1) and "simian"IV from chimpanzees (cpz) are more in the assigned name considering SIVcpz and HIV-1 share more homology than SIVs that infected different old world monkeys(1-4). Zoonotic transmissions of SIV occurred through several independent jumps from chimpanzees to humans leading to the establishment of 4 groups within HIV-1 ( $M, N, O$ and $\mathrm{P})$ and from sooty mangabeys to humans for the 9 groups (A-I) within HIV-2(1-7). HIV-1 group $M$ is the most prevalent human lentivirus accounting for $>95 \%$ of the 36 million infections in humans while HIV2 and HIV-1 group O are responsible for $1-2$ million and $<30,000$ infections, respectively $(2,8)$. The rare HIV-1 groups $\mathrm{N}$ and $\mathrm{P}$ are found in less than a hundred individuals residing in or visiting Equatorial rainforest of West and Central Africa(2,9-13), also the origin of HIV-1 group M zoonotic jump. West Central African countries with Cameroon at its epicenter, represent the oldest epidemic illustrated by high HIV genetic variability in the current infected population $(2,13)$.

There are more than 40 different SIV lineages infecting more than 45 species of African non-human primates, most commonly chimpanzees, gorillas and other old world monkeys(35,14-16). As an example, SIVsmm infects sooty mangabeys (smm) (or Cercocebus atys) in West Africa and is the likely source of HIV-2(17-19). SIVcpz infects the Pan troglodytes troglodytes $(P t t)$ and Pan troglodytes schweinfurthii (Pts) sub-species of chimpanzees common in central and west central Africa(7,20-22). While SIVcpz from Ptt is the origin of HIV-1 groups M and N, Pts related SIV lineages have not been found in humans $(7,22,23)$. Likewise, SIVcpz has not jumped to other subspecies of chimpanzees (i.e. Pt verus or vellerosus or bonomos) which raises the possibility of incompatibility or lack of opportunity for this cross-species transmission(24-27). It is still unclear if SIV infecting lowland gorillas (Gorilla gorilla or gor) inhabiting the Equatorial forest 
of Central Africa $(15,16)$ were the direct link for the primate lentiviral jump to humans to establish HIV-1 groups $\mathrm{O}$ and $\mathrm{P}$ or if this jump involved chimpanzees as an intermediate host.

A cross-species lentiviral inoculation establishing a new, successful zoonosis may be governed by higher replicative capacity $(2,28)$ and reduced sensitivity to innate restriction factors in the new primate host $(22,29)$. As an example, increased sensitivity to human restriction factors or low replicative fitness of SIVcpz from Pts chimpanzees in susceptible human CD4+ cells may have prevented this cross species transmission. Alternatively, humans were never exposed to an SIV from infected Pts chimpanzees. Given the deforestation and exploitation in sub-Saharan Africa after the turn of the $18^{\text {th }}$ century, a time which coincided with the introduction then rapid expansions of the HIV-1 and -2 epidemics, it is unlikely but not impossible that humans were only exposed to SIV from Ptt and not Pts chimpanzees. Primate lentiviruses have been jumping and circulating through old world primate populations, including humans, for thousands of years(30). Cross-specific transmission and variable host adaptions likely resulted in extinction of many primate lentiviral lineages, attenuations, and even the birth of novel lineages through recombination events that occur during super-infections with SIVs of different primates(31-34). In fact, SIVcpz are recombinants between two lentiviruses originating from the red capped mangabey and greater spot-nosed monkey or a closely related species(35).

Following the zoonotic transmission to humans around the 1920s, HIV-1 group M rapidly evolved into 10 different subtypes within the Congo Basin but with increased human migration and trade with sub-Saharan Africa, many HIV-1 subtypes founded new epidemics across the globe and even recombined to generate new circulating recombinant forms (CRFs)(2)(1,36). This collection of group M subtypes have evolved almost equidistant from the root of the HIV tree but despite the similar evolutionary rates, considerable differences in virulence and transmission efficiency may still be shaping subtype spread(37-39). In particular, HIV-1 subtype D may be the most virulent in humans $(37,40,41)$ but has decreased in prevalence in the past 30 years whereas 
the rapid expansion and predominance of HIV-1 subtype C worldwide may be related to its lower virulence and average transmissibility(2). Following thousands of pairwise competitions of HIV-1 in human peripheral blood mononuclear cells (PBMCs), primary T cells, macrophages, tonsillar tissue, and DC-T cell cocultures, we have established a rank order in replicative or "pathogenic" fitness: HIV-1 groupM/subtype $F \geq B=D=C R F 12,17 \_B F>A=C R F 02 \_A G=C R F 01 \_A E>C>$ HIV-1 grpO > HIV-2(38,42,43). Although HIV-1 replicative fitness in primary $\mathrm{T}$ cells and macrophages is a strong correlate of disease progression in humans $(37,44,45)$, this relationship is not absolute especially with HIV-2 in humans and some SIV strains in African green monkeys (agm) and chimpanzees(46-52). A better surrogate of virulence may be direct infection of primary lymphoid organs like tonsillar tissue in which viral pathogenicity, T-cell depletion, and viral propagation rates can be measured(53,54).

In the present study, we utilized various primary human cell types to determine the ex vivo fitness and pathogenicity of a diverse set of 21 primate lentiviral isolates that included HIV-1 groups M, N, O, HIV-2, and SIVs of cpz, gor, mac, smm, and agm. We have performed over 300 pairwise dual infections using the 21 primate lentivirus isolates in peripheral blood mononuclear cells from both human and chimp (Pan troglodytes verus; Ptv) donors, along with monoinfection of PMBCs and cell lines, and finally dendritic cell-mediated transinfections of human (Homo sapiens; Hs) PBMCs. We determine the relative repression of primate lentivirus replication in human cells by various restriction factors and correlated this to replicative fitness. Finally, we accessed the cytopathogenicity on CD4+ T cells in human tonsillar explant tissue following infection with the HIV-1, HIV-2 and SIV isolates. Our results show that SIV strains from chimps and gorillas had similar ex vivo fitness as HIV-1 group M strains in both human and chimp PBMCs, while HIV-1 group O, SIVmac/smm, and HIV-2 isolates had sequentially lower fitness. Based on the higher relative fitness and reduced restriction on SIVcpz-Ptt in human T-cells compared to that of SIVcpz-Pts or any other SIV strain, we provide experimental evidence that SIVcpz from 
bioRxiv preprint doi: https://doi.org/10.1101/2020.10.13.337303; this version posted October 13,2020 . The copyright holder for this preprint (which was not certified by peer review) is the author/funder, who has granted bioRxiv a license to display the preprint in perpetuity. It is made available under aCC-BY 4.0 International license.

Ptt was most adapt in establishing infection in humans. However, this initial zoonotic transmission to humans was likely non-pathogenic based on tonsillar tissue studies. 


\section{RESULTS}

HIV-1, HIV-2 and SIV replication in human PBMCs and U87 cell line.

Twenty-six HIV and SIV strains representing 10 HIV-1 group M, 3 group O, 1 group N, 6 SIVcpz, 1 SIVgor, 2 HIV-2 and 1 each of SIVsmm, SIVmac and SIVagm (Figure 1A and B) were propagated on either U87.CD4.CCR5 cell line or human PBMC. Infectious titer was determined in human PBMCs using a standard $\mathrm{TCID}_{50}$ assay (Figure $\left.1 \mathrm{~B}\right)$. All isolates were R5 as confirmed by their replication on U87.CD4.CCR5 but not U87CXCR4 cell lines. Genotypes were confirmed through Sanger sequencing and phylogenetic analyses of gag and env; neighbor-joining trees shown in Figure 1A and Supplementary Figure 1. The group M strains clustered more closely with SIVcpz MB897 (Fig 1A) while SIVgor_CP684 grouped with the group O strains, as previously described (Fig 1A and B). SIVcpz EK505 is more closely related to the HIV-1 group N strain, YBF30. The HIV-2 strains VI1835 and VI1905 (both subtype A) clustered with SIVsmm, the source of HIV-2 (Fig 1A; Supplementary Figure 1).

The replication kinetics of all the primate lentiviruses were determined on human PBMCs and the brain glioma cell line U87 expressing huCD4 and either from human $(H s$ for Homo sapiens) CCR5 or rhesus macaque (Mm for Macaca mulatta) CCR5. All cell types were infected with the same $\mathrm{MOI}$ and monitored for virus production (and cell viability, see below) for 12 days to determine the amount of reverse transcriptase (Methods). Virus replication kinetics over a course of a 12 day infection in PHA/IL2-treated human PBMCs (as measured by area under the RT activity curve) were not significantly different between the HIV-1 group $M, O$ and SIVcpz strains (Fig 2A). In the human brain glioma cell line expressing HsCD4 with HsCCR5 or MmCCR5, the HIV-1 group M strains had 10-fold and nearly 100-fold greater replication kinetics than HIV-1 group O and SIVcpz strains, respectively (Figure 2A). When comparing growth kinetics for specific primate lentivirus strains, the HIV-1 group M subtype A strain, A74 (Fig 2Bi) replicates more 
efficiently in the U87 cell lines than in human PBMCs whereas the human lentiviruses, HIV-1 group O CM02-41 (Fig 2Bii) and HIV-2 VI1835 isolates (Fig 2Biii) replicate to similar levels in PBMCs and the U87 cell lines (with Hs or MmCCR5). However, the SIV strains of chimpanzees (cpz) (Supplemental figure 2) and of African green monkeys (agm) (Fig 2Biv) replicated at higher levels in HsPBMCs than in U87 cells. We propose that the HIV-1 group $M$ is more adapt to replication in many human cell types aside from just CD4+ T-lymphocytes as compared to HIV-1 group $\mathrm{O}$ and HIV-2.

\section{Dendritic cells enhance HIV and SIV infection in PBMCs}

Within a human host, activated CD4+ T-cells in the gut, lymph nodes, and other tissues may be responsible for the majority of HIV-1 replication. T-cell activation and delivery of the HIV may be mediated by direct dendritic cell contact. The replication of primate lentiviruses in PBMCs mediated by human MDDC trans-infection was significantly greater (2- to 3-fold) than that observed in direct lentivirus exposure of PHA/IL-2 treated PBMCs of the same donor (Supplementary Fig.2). The highest fold change (ca. 3-fold) in replication mediated by DCs was observed with the HIV-1 group M A74 virus (Supplementary Figure 2B). In using the MDDC and PBMCs of a different donor, we observed a similar level of enhancement of lentiviral replication with MDDC-mediated trans infection.

\section{Competitions of HIV and SIV isolates in human and chimpanzee PBMCs}

Due to the inherent variation of culture conditions, logarithmic growth of viruses, and variability in viral monitoring assays, only gross differences in replication kinetic of different lentiviruses can be measured in monoinfection $(45,55,56)$. Direct dual virus competitions at low multiplicity of infection in the same contained culture provides a relative, reproducible measure of replicative fitness with minimal variance $(42,44,45,55,57)$. Thus, we performed pairwise competitions with 21 lentiviruses in both human and chimpanzee PBMCs using viruses 
(schematically illustrated in Figure 3A). A total of 253 separate pairwise competitions in HsPBMC at an $\mathrm{MOI}$ of 0.005 were harvested after 12 days post infection, i.e. peak virus production. Dual infections at this $\mathrm{MOI}$ and in this time frame limits recombination to $<0.1 \%$ of the observed dual virus replication(44,58,59). We obtained a limited supply of blood/PBMCs from P.t. verus (Ptv) to perform 82 pairwise competitions involving inter-lentiviral pairs (e.g. HIV-1 M strain versus SIVcpz rather than HIV-1 M subtype A versus HIV-1 M subtype B). Ptv was selected for PBMCs since this chimpanzee subspecies lacked infection by SIVcpz (as tested to date)(24-27). For intergroup/type competitions performed in both $\mathrm{Hs}$ and PtvPBMCs, the extracted DNA was PCR amplified in a gag coding region, that is conserved among primate lentiviruses. Extracted DNA from intra HIV-1 group M competitions were amplified using the envelope primers described previously $(42,44,55,57,60,61)$ (Figure 3A). PCR products were barcoded and sequenced by next generation deep sequencing. We then processed resulting reads through the SeekDeep pipeline which performs de novo clustering at a single base resolution(62). SeekDeep is advantageous as resulting measures are centered around the most abundant viral clones in the quasispecies/swarm and thereby avoid biases that may be engendered by direct mapping to a singular strain reference sequence.

Supplementary figure 3 provides the detailed results from 335 individual competitions involving each pair of primate lentiviruses in human and PtvPBMCs. Figure 4 provides the competition results of each primate lentivirus of different groups/types against HIV-1 group M isolates (Figure 4A and C) or SIVcpz isolates (4B and D) in HsPBMCs (4A and B) and PtvPBMCs (4C and D). In direct competitions, the human lentiviruses HIV-1 group $\mathrm{O}$ and HIV-2 were significantly less fit than SIVcpz and HIV-1 group M isolates in either HsPBMCs (Fig. 4A) or ptvPBMCs (Fig. 4C) (ANOVA; Supplementary tables). Interestingly, SIVgor CP684 and SIVcpz strains, the progenitors of HIV in humans, could outcompete most HIV-1 group M isolates in HsPBMCs (Fig. 4A) whereas HIV-1 and its progenitor, SIVsmm has the lowest replicative fitness. 
We were unable to propagate sufficient HIV-1 P RBF168 for this study but the SIVgor CP684 was over $90 \%$ identical in Gag, Pol and Env sequence to groups $\mathrm{O}$ and $\mathrm{P}(16)$, very similar to the homology between HIV-1 groups $\mathrm{M}$ and $\mathrm{N}$ and their respective SIVcpz progenitor.

In the competitions involving SIVcpz and HIV-1 group M in HsPBMCs (Figure 4A and C), and the reciprocal plot in Figure 4B and D in PtvPBMCs, SIVcpz strains trended to slightly higher replicative fitness than HIV-1 group $M$ isolates. Again, the other SIV strains (not infecting chimpanzees) or the HIV-2 strains (originating from SIVsmm) were less fit than SIVcpz or group M HIV-1 in both Hs and PtvPBMCs. HIV-2 or SIVsmm have not been identified in chimpanzees. Despite lower replicative fitness of HIV-1 group O versus M (Figure 4A\&C), SIVcpz was only more fit than HIV-1 group O in PtvPBMCs (Figure 4B) but not in HsPBMCs (Figure 4D). The path of zoonotic jumps responsible for the origin of HIV-1 group O is not well defined and may involve an intermediate jump through chimpanzees(16,63).

The competition results are also presented as the replicative fitness values of each primate lentivirus within a group/type competed against the primate lentiviruses outside of this group/type in HsPBMCs (e.g. HIV-1 group M isolates competed against HIV-1 O, N, HIV-2, SIVcpz, gor, agm, and mac; first bar in Figure 4E). HIV-1 groups $\mathrm{M}, \mathrm{N}, \mathrm{SIVcpz}$ and gor are significantly more fit than HIV-1 group O, HIV-2, SIVagm and mac (Figure 4E; ANOVA analyses in Supplementary tables).

\section{Replicative fitness differences among SIVcpz strains derived different chimpanzee subspecies}

When comparing the replicative fitness of SIVcpz versus HIV-1 group M in HsPBMCs and PtvPBMCs, there were SIVcpz strains/viruses with high and low fitness. The competitions included SIVcpz_ptt isolated from the Pan troglodytes troglodytes subspecies and SIVcpz_pts found in the $P$. troglodytes schweinfurthii. SIVcpz_ptt strains were significantly more fit than 
SIVcpz_pts compared to HIV-1 group $\mathrm{M}$ in both $\mathrm{Hs}$ (Figure 5A) and PtvPBMCs (Figure 5B) (ANOVA; Supplementary tables). The SIVcpz_ptt strains, EK505 and MB897 could equally compete with the more fit group $M$ isolates, $A 1, A 74, B 5$, and $B 6$ whereas the SIVcpz_pts strain, Nico-0 and Noah-20 were out-competed in HsPBMCs (Figure 5C). Gab1, the least fit SIVcpz_ptt strain was outcompeted by group M strains of high fitness but like all the SIVcpz strains, could compete with the HIV-1 group $M$ isolates of the lowest replicative fitness (Figure $5 D$ ). It is important to stress that SIVcpz strains appeared most adapt at replicating in HsPBMCs as compared to SIVsmm, SIVmac, and SIVagm, the latter of which replicated with slow kinetics on HsPBMCs or susceptible primate cell lines (Figure 2 and 4). Among the SIVcpz strains, those isolated from Pan troglodytes troglodytes shared the closest genetic identity to group M (Figure 1) and were more adapted to replicating in human primary cells than SIVcpz from $P$. troglodytes schweinfurthii, a chimpanzee subspecies found primarily in West and East Africa and less in the Congo basin of Central Africa. Thus, the inherently higher replication fitness of SIVcpz_ptt versus SIVcpz_pts could have contributed to the cross-species transmission of the latter and evolution into HIV-1 Group M.

\section{Impact of human restriction factors on primate lentivirus replication}

Host factors such as Trim5a, APOBEC 3F/G/H, tetherin/BST2, and SamHD1 have all been shown to restrict xenotropic retrovirus replication and most have been associated with preventing cross species transmission of primate lentiviruses $(29,64)$. We explored the ability of these restriction factors in human cells to reduce replication kinetics of NHP lentiviruses as one mechanism to prevent a jump into humans. For these studies, we utilized the cell line (U87.CD4.HsCCR5) most supportive of HIV-1 group M replication and most restrictive to NHP lentiviral replication (Figure 2). In cells treated with siRNAs reducing the endogenous mRNA of Trim5 $\alpha$, tetherin/BST2, APOBEC 3F and 3G (by $80-90 \%$ for 5 days), we observed release of restriction and increase in lentivirus replication (Figure 6 and Supplementary Fig. 4). Reduction 
of human APOBEC3F and 3G levels resulted in minimal increases in lentiviral replication over 7 days (Supplementary Fig.4C and D), which is expected based on this restriction requiring an accumulation of deleterious mutations. Human Trim5 $\alpha$ results in low level inhibition of all primate lentiviruses which is released with siRNA treatment (Supplementary Figure 5A). Trim5 $\alpha$ is a stronger NHP restriction factor to prevent cross-species replication of lentiviruses. The strongest restriction of NHP lentiviruses in these human cell lines appears to be mediated by tetherin/BST2 (Figure 6 and Supplementary Fig. 4). SIVmac and SIVman replication increased by 5-6 fold with a $>80 \%$ knockdown of tetherin mRNA over a 9 day infection. Tetherin inhibits even HIV-1 group $\mathrm{M}$ and $\mathrm{O}$ isolates at a low level. In contrast, there was no apparent inhibition of SIVcpz strains by human tetherin.

Based on the pairwise virus competitions with the 21 lentiviruses performed in HsPBMCs, we calculated the average replicative fitness value of each lentivirus based on only the intergroup/type competitions and removing all intragroup/type fitness values (excluding e.g. group M A74 versus group M B5). As described in Supplementary Figure 5, the average intergroup/type fitness was consistent with replicative fitness derived from every competition against an HIV-1 group M or SIVcpz isolate as described in Figure 3. The average intragroup/type fitness values of each of the 21 lentiviruses were then compared to the relative restriction by human Trim $5 \alpha$ (i), Tetherin (ii), APOBEC 3F (iii), and 3G (iv) and we observed no significant correlations (Figure 7A). However, when the average fitness of only SIVs were plotted, a significant inverse correlation was observed between replicative fitness and release of restriction by Trim $5 \alpha$, Tetherin, or the additive effects by all four factors (Figure 7Bi, ii, and v). Again, the SIVcpz strains (especially $c p z \_P t t$ ) had the highest replicative fitness and appeared to be the least restricted in human cells.

\section{Cytopathic phenotype of HIV-1, HIV-2 and SIV in ex-vivo lymphoid tissues}


Unlike PBMCs, human tonsils are permissive cells that do not require stimulation with mitogens or IL-2 for HIV propagation(65). To determine the cytopathic effect and CD4 T-cell depletion rate by these primate lentiviruses, human tonsils were infected with the same infectious titers and monitored for virus production and CD4 T-cell depletion based on pyroptosis and/or necrosis relative to uninfected controls $(53,54)$. It is important to note that depletion of CD4 T-cell in human tonsils by R5-using HIV-1 subtype B strains (average of $10 \%$ herein with the HIV-1 group $M$ isolates) is lower than reported with X4-using HIV-1 strains, typically reaching a $65 \%$ loss in tonsillar CD4+ T cells(54). In this study, the highest CD4+ T cell depletion was observed with SIVmac (average 27\%), followed by A74 (18\%), VI1835 (16\%) and D107 (12\%) (Figure 8A). Despite the relatively low replication in CD4+ T-cells, HIV-2 and SIVmac/agm still depleted significant levels of CD4 T-cells in human tonsils (Figure 8B). Exposure to the human tonsillar tissue to SIVcpz strains (Ptt and Pts) resulted in minimal CD4+ T cell depletion (1 to 3.5\%; Figure 8A) despite high levels of replication in these tissues (Figure 8B). SIVcpz_Pts Nico had the highest ratio of virus production versus CD4+ T-cell depletion in the tonsillar tissues. All the primate lentiviruses within HIV-1 groups (M, N, O), HIV-2, SIVgor and SIVagm/mac were significantly better at depleting CD4 T-cells than SIVcpz (except group N and SIVgor, limited data points). In contrast, there was no difference in the levels of CD4 T-cell depletion in the tonsillar tissues between any of the types/groups when SIVcpz was not included in the ANOVA analyses.

No correlation was observed between the relative replication in the tonsillar tissue and the level of CD4 depletion by these viruses. SIVcpz had the highest replicative fitness in human PBMCs and in the tonsillar tissues. In contrast, SIVcpz infection was associated with minimal cytopathogenicity in human tonsillar tissue resulting in the greatest ratio of virus production to CD4+ T cell death of any primate lentivirus (Figure 8C). In contrast, the HIV-2 isolates, SIVagm, and SIVmac showed an average depletion of CD4+ T cells, i.e. comparable to that observed with HIV-1 group M, O, and all other primate lentiviruses (except SIVcpz) (Figure 8A and B). Based 
on the poor virus production in human tonsillar tissue (as well as average fitness in HsPBMCs), the ratio of replication to CD4 T cell depletion of HIV-2 and SIVagm/mac was the lowest for all primate lentiviruses (Figure $8 \mathrm{C}$ ). As described below, these findings might suggest that pathogenicity/virulence could have evolved as a trait in humans following a zoonotic jump. 


\section{Discussion}

Phylogenetic studies have revealed a complex history of interspecies jumps of lentiviruses among catarrhine monkeys or "old world" monkeys. Based on the discovery of an endogenous primate lentivirus in lemurs of Madagascar, best estimates place the introduction of lentivirus into monkeys approximately 17 million years ago from a jump of a primordial lentivirus which then branched into FIV and SIV(66). Despite evidence of primate lentiviruses in old world monkeys for millions of years, our knowledge of this evolution is largely based on the jumps during the past 10,000 years resulting in the existing lentiviral lineages in primates, many of which are unstable in their current host species. An example of this instability is the jump of SIV from sooty managabeys into humans in 1930 s(67) which resulted in HIV-2 with a peak epidemic of 1-2 million, limited transmission success, and the progressive loss in prevalence within humans, even before the introduction of antiretroviral treatment. HIV-1 group $\mathrm{O}, \mathrm{N}$, and P had even less success surviving in humans following introductions from the gorilla and/or chimpanzees; jumps dated to sometime in the 1920 s for group $\mathrm{O}$ and 1960 s for $\mathrm{N}(22,67,68)$. In contrast, HIV-1 group M emerged in humans with a jump from chimpanzees $(P t t)$ in the Congo basin after the turn of the $19^{\text {th }}$ century, an event that has now resulted in over 40 million deaths with another 37 million infected humans(67-69). There is no clear evidence of attenuation of HIV-1 virulence or reduction in transmission efficiency but some in vitro studies suggest this possibility $(39,70)$.

This study was designed to compare the competitive replicative fitness and virulence of different lentiviral strains isolated from various primate species. Exposure of a primate to a xenotropic lentivirus is unlikely to result in a cross-species transmission event due in part to protective barriers, e.g. innate defenses and various restrictions factors. Nonetheless these restriction factor/innate defenses appear to show variable protection against different, foreign lentiviruses. To understand the overall restriction of primate lentiviruses in primary human cells susceptible to HIV, we compared the replicative fitness of primate lentiviruses in both human and 
chimpanzee PBMCs by performing over 250 with 21 lentiviral isolates of HIV-1 groups $\mathrm{M}, \mathrm{N}, \mathrm{O}$, HIV-2, SIVcpz, gor, smm, and agm. To determine relative virulence upon a possible jump to humans, we compared the relative replicative fitness of these primate lentiviruses to the inhibition by various human restriction factors and the relative depletion of CD4+ T cells in human tonsillar tissue.

To summarize, SIV strains from Ptt and Gor and HIV-1 group N appeared slightly more fit than even HIV-1 group M replicating in both human and chimp PBMCs. However, as previously published, there was a wide range in replicative fitness among HIV-1 group M subtypes with subtype $A$ and $C$ strains again being consistently less fit $(37,42,55,57)$. When these HIV-1 group M strains of lower fitness were removed from the analyses, there was no significant difference in the replicative fitness of SIV from chimpanzees and gorillas and the HIV-1 group M and group $\mathrm{N}$ isolates found in humans. SIVcpz or SIVgor (progenitor of HIV-1 group P) are significantly more fit than HIV-1 group O in human PBMCs. Finally, SIV from African green monkeys and Sooty mangabey had the lowest replicative fitness in both human and chimp PBMCs, similar to the low replicative fitness observed with HIV-2. We determined that the relative level of replication of these non-human primate lentiviruses in human and chimp PBMCs reflect the cumulative inhibition by the various human restriction factors, with tetherin/BST2 being the most restrictive. Based on the cumulative data presented herein, it is clear that SIVcpz and SIVgor have the greatest ability to replicate in human PBMCs. However, the SIVcpz derived from Pts, which did not establish lentivirus epidemic in humans, was less fit in human PBMCs than SIVcpz of Ptt. SIVcpz from Pts or Ptt were also inhibited the least by human restriction factors. Based on the similar overlap and invasion of humans into the Pts and Ptt habitats in the Rift Valley of East Africa, Congo Basin of Central Africa, and the tropical south of West Africa, it is unlikely that humans would be exposed less to Pts than to Ptt chimpanzees. Findings presented herein suggest that the SIVcpz of Ptt compared to SIVcpz of $P$ ts was more compatible for cross species 
transmission to humans and gained the foothold necessary for transmission and human adaptation.

The ability of a lentivirus to replicate in the primary susceptible cells in a host does not always correlate with pathogenesis. A strong example is the lack of disease in African Green Monkeys despite the high viral loads of SIVagm produced by an abundance of infected T-cells in these animals $(46,47)$. There has only been one study that has characterized disease progression of a chimpanzees infected by SIVcpz (a Pts strain) in the wild but raised in captivity. With this animal there was little evidence of disease despite an increasing viral load during the length of infection(48). In humans, several studies have described a direct correlation between the rate of disease progression and the replicative fitness of the infecting HIV-1 isolates in primary Tcells $(37,44,45,71)$. This is best illustrated by the low replicative fitness of HIV-1 isolates derived from patients with slow or non-progressing disease versus the high replicative HIV fitness among rapid progressors. In this study, we compared the cytopathogenicity of these primate lentiviruses in primary human lymphoid tissue, i.e. resected tonsillar tissue. There was a clear disconnect between the ability of non-human primate lentiviruses to propagate in human tonsillar tissue and the pyroptosis/cell death of the CD4+ T cells within the same tissue. Similar levels of T-cell death was mediated by HIV-2, SIVagm, and SIVsmm with low replicative fitness than by HIV-1 group $\mathrm{M} / \mathrm{N}$ and SIVgor with high replicative fitness. In contrast, SIVcpz having the highest replicative fitness in tonsillar tissue (as well as in human and chimp PBMCs) was associated with minimal pyroptosis and all manner of T-cell death in this tonsillar tissue. The inability of SIVcpz to mediate cytopathogenicity in human T-cells may correspond to the minimal pathogenesis or lack of disease described in most SIV infected chimpanzees $(48,49)$. Again, in contrast to the most fit SIVcpz's, SIVsmm (the progenitor of HIV-2) and HIV-2 were highly cytopathogenic in these tonsillar tissues despite having the lowest replicative capacity. These findings are consistent with slow disease progression associated with HIV-2 infected humans(51,52). HIV-1 group O and 
SIVgor (the progenitor of HIV-1 group O) had high cytopathogenicity and moderate replicative fitness in these tonsillar tissues but not as low as HIV-2/SIVsmm. HIV-1 group O infected humans progress faster to disease than those infected with HIV-2 but slower than those infected with HIV1 group $M(63)$.

The relative virulence of a virus in their host species is of course impacted by a multitude of host factors (e.g. innate and acquired immune responses, restriction factors). We propose that lentivirus virulence following cross-species transmission may relate to replicative fitness and per virus pathogenicity, both of which are influenced by the level of inhibition by innate restriction factors. This hypothesis appears to apply with the SIVgor and SIVsmm establishing the group O and HIV-2 spread in humans(2,22,68). Despite the close genetic relationship of SIVcpz_Ptt and HIV-1 group $M$, the SIVcpz strains from Ptt and Pts and HIV-1 group $M$ strains had similar replicative fitness in human cells but the SIVcpz strains did not result in cytopathogenicity due to bystander effects or direct infection. This inconsistency between SIVcpz_Ptt and HIV-1 could relate to an adaptation/evolution of SIVcpz in humans to escape restriction factors/barriers following a jump. However, there is little evidence that SIVcpz is restricted from replication in human PBMCs as are other SIV lineages. It is feasible that an increased cytopathogenicity evolved early in the human epidemic during a period of high viral burden and efficient transmission. As HIV-1 group M diversified during the past 100 years, HIV-1 subtypes may have evolved with differences in virulence and transmission efficiency. Increase virulence of HIV-1 subtype $D$ over subtypes $A$ and $C$ has been well documented within infected cohorts and using similar ex vivo studies described herein $(37,40,42,55,57)$. It is also feasible that the HIV-1 epidemic relates to the cross-species transmission of a rare SIVcpz strain resulting in exceptionally high virulence (replicative fitness + cytopathogenicity) in humans. The chimpanzees carrying this SIVcpz may now be extinct. The rarity of this SIVcpz strain in chimpanzees might explain why a lentiviral epidemic did not appear earlier in human history considering the clear interaction of 
bioRxiv preprint doi: https://doi.org/10.1101/2020.10.13.337303; this version posted October 13, 2020. The copyright holder for this preprint

(which was not certified by peer review) is the author/funder, who has granted bioRxiv a license to display the preprint in perpetuity. It is made available under aCC-BY 4.0 International license.

chimpanzees and humans in central Africa. With this scenario, the HIV subtypes may have evolved with differential reductions in virulence and transmission efficiencies in humans. Clearly, neither of these hypotheses can be proven without the availability of human lentiviral samples closer to the cross-specific transmission event responsible for the HIV-1 epidemic. 


\section{MATERIALS AND METHODS}

\section{Cells}

Primary and Cell lines

HIV negative subjects provided whole blood from which peripheral blood mononuclear cells (PBMC) were separated using the Ficoll-Hypaque density centrifugation technique. Whole blood from Chimpanzee was obtained from an HIV negative Chimpanzee (Pan troglodytes verus) from the Texas Primate Facility and shipped overnight to Case Western Reserve University, Cleveland and PBMCs were separated as described above. All PBMCs were stimulated for 3-4 days with $2 \mathrm{ug} / \mathrm{ml}$ of phytohemagglutinin (PHA; Gibco BRL) and $1 \mathrm{ug} / \mathrm{ml}$ of interleukin-2 (IL-2; Gibco BRL) in complete RPMI 1640 containing 2mM L-glutamine. U87 human glioma cells expressing CD4 and CCR5 were obtained through the AIDS Research and Reference Reagent Program and in maintained in DMEM supplemented with 10\% FBS, Fetal Bovine Serum (FBS; Mediatech, Inc.), Penicillin (100 U/ml), Streptomycin (100 ug/ml), Puromycin (1ug/ml) and G418 (300 $\mu \mathrm{g} / \mathrm{ml}) .293$ T-cells (human embryonic kidney cells) were grown also grown in DMEM media.

\section{Human tonsils}

Human tonsils removed during routine tonsillectomy (provided by the Human Tissue Procurement Facility of the University Hospitals Case Medical Center Hospital, Cleveland, Ohio) was received within $5 \mathrm{hrs}$ of excision. Use of anonymous surgical waste for experimental HIV infections was approved by the IRB under UHIRB 01-02-45. To prepare human lymphocyte aggregate cultures (HLACs), we removed the cauterized tissue from the tonsil as well as the capsule and the fatty parts surrounding the tonsil. Bloody or inflamed parts were also discarded from the tissue. The tonsil tissue was dissected into small pieces by hand with a surgical scissors and the pieces were squeezed using a flat surface. Cells were dispersed and washed in 


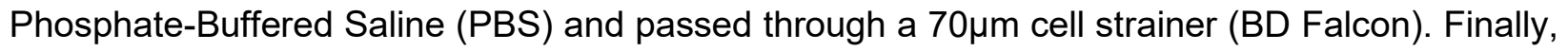
isolated HLACs were plated in 96-well U-bottomed plates (Corning, Inc.) at a concentration of $2 \times 10^{6}$ cells per well in $200 \mu \mathrm{l}$ RPMI 1640 media containing $10 \%$ FCS, $100 \mathrm{U} / \mathrm{mL}$ penicillin, 100 $\mu \mathrm{g} / \mathrm{mL}$ streptomycin sulfate, $2.5 \mu \mathrm{g} / \mathrm{ml}$ fungizone, $2 \mathrm{mM}$ L-glutamine, $10 \mathrm{mM}$ HEPES, $1 \mathrm{mM}$ sodium pyruvate and $1 \%$ non-essential amino acids mixture. One day after HLACs preparation, cells were inoculated with virus in triplicate ( 0.002 multiplicity of infection; (MOI) per $2 \times 10^{6}$ cells per well in $200 \mu \mathrm{l})$. After overnight infection, cells were washed, and supernatants harvested at days 4,7 , and 10 post infection without dispersing the pellet. Lentiviral replication was assessed using an RT assay as described previously(72).

\section{Monocyte-derived dendritic Cells (MDDCs)}

MDDCs were isolated as described previously(73). Briefly, CD14+ beads (Miltenyi Biotech) were used to isolate $\mathrm{CD} 14^{+}$monocytes from healthy donor human PBMCs. These were then cultured in the typical $10 \%$ FBS/RPMI media and supplemented with $10 \mathrm{ng} / \mathrm{ml} \mathrm{IL-4}$ and $50 \mathrm{ng} / \mathrm{ml}$ GM-CSF (Miltenyi Biotech). MDDCs were matured by overnight stimulation with 100ng/ml LPS (Sigma) 5-6 days after initiation of the cultures. Mature MDDCs were pelleted, washed and resuspended in fresh medium ready for co-culture with PBMCs and infection with viruses.

\section{Viruses}

Twenty six primate lentiviruses, primary isolates or molecular clones were used for this study and included HIV-1 group $M(n=10), N(n=1)$ and $O(n=3)$, and HIV-2 $(n=2)$ and from nonhuman primates; SIVcpz $(n=6)$, SIVgor $(n=1)$, SIVagm $(n=1), \operatorname{smm}(n=1)$, and mac $(n=1)$. A full list of the viruses, their origins, phylogenetic relations in env and gag, titers are outlined in Figure $1 \mathrm{~A}$ and $\mathrm{B}$. The HIV-1 group $\mathrm{M}$ and group $\mathrm{O}$ isolates have been used previously(42) and most were originally obtained from the AIDS Research and Reference Reagent Program of the National Institute of Health. The well characterized group molecular O clone CMO2.41 was also used as 
one of the representatives of HIV-1 group O(74). SIVgor (CP684) and three of the SIVcpz strains (EK505, Gab1-1, MB897-1) were gifts from Beatrice Hahn. The remaining SIVcpz and SIVagm, smm, and mac isolates were provided by the Institute of Tropical Medicine in Antwerp, Belgium. The SIVcpz strains Nico and Noah were obtained from a chimpanzee infected in the wild, maintained in captivity, and whose virus was then used to infect another chimpanzee(48).

Plasmids of the proviral clones (CMO2.4, CP684, EK505, Gab1-1, MB897-1) were used to generate infectious virus by transfecting $293 \mathrm{~T}$ cells using the Effectene transfection reagent (QIAGEN, Valencia, CA). Supernatant containing virus was collected 2 days post transfection, clarified by centrifugation at 2,500 rpm for 10 mins and purified through a 0.45 um pore-size filter (Millipore, Billerica, MA). Transfection derived supernatants were subsequently briefly passaged in either human PBMC while all other primary isolates were briefly passaged in PBMCs to generate virus stocks. The tissue culture infectious dose for $50 \%$ infectivity $\left(\mathrm{TCID}_{50}\right.$ expressed as $\mathrm{IU} / \mathrm{ml})$ ) of propagated viruses was calculated by the Reed and Muench method as described previously(42). Virus productions in supernatant was determined by a positive RT activity (two standard deviations above the negative control). RT activity is the preferred assay considering the enzyme is present in all HIV or SIV strains.

\section{Assessment of CD4+ ${ }^{+}$-cell depletion and RT activity in human tonsil histocultures}

Twelve days post infection, HLACs were analyzed by fluorescence-activated cell sorting (FACS). Uninfected and infected HLACs were stained with Live/dead ${ }^{\circledR}$ violet (Invitrogen, Grand Island, NY), Annexin V-APC (e-biosciences, San Diego, CA) and with cell surface markers $\alpha$ human CD4 PE (Biolegend, San Diego, CA), $\alpha$-human CD3 PerCP (BD Biosciences) and $\alpha$ humanCD8 FITC (BD Pharmigen). Cells were acquired in a LSRIl flow cytometer (BD Biosciences, San Jose, CA) and data analyzed with FloJo software (Tree Star, Inc. Ashland, OR). Supernatants from each tonsil infection was also assayed for RT activity(72). 


\section{Ex-vivo growth competition assay}

Ex vivo pathogenic fitness for the isolates was determined by infecting human and chimpanzee PBMCs using methods described previously(42,44,55,57,60,61). In human PBMC, pathogenic fitness of HIVISIV isolates was performed by full pair wise competition using 9 group M (2 each of subtypes A, B, D; and 3 C), 3 group O, 1 group N, 5 SIVcpz ( 3 from Ptt and 2 from Pts), 2 HIV-2 and 1 each of SIVsmm, agm and mac. For chimpanzee PBMC the competition was restricted to a selected number of isolates due to the limitation of cell number. All competitions were performed in 48 well plate containing $2 \times 10^{5}$ PBMCs and equal multiplicity of infection (0.005) for both viruses, i.e. 1000 IUs. Virus production was monitored by measuring the RT activity until peak production at day 12 when cells were harvested and stored at $-80^{\circ} \mathrm{C}$.

\section{PCR and sequence analyses}

Due to the closer genetic relationship between HIV-1 group M, DNA extracted from intraHIV-1 group M competitions were PCR amplified using envelope primers described previously $(42,44,55,57,60,61)$. Briefly, C2-C3 region of envelope was amplified by PCR using the primers E80 and E125 primers(44). For the DNA extracts of the competitions using the more divergent HIV-1/HIV-2/SIV viruses, conserved primers that spanned the primer binding site (PBS) PBSdt-F AAAATCTCTAGCAGTGGCGCCCGAACAG (position 622-649 in HxB2; 806-835 in SMM239) and the 5' end of gag (MAp17) GAGdt-R TTTCCAGCTCCCTGCTTGCCCATACTA (position 890-916 in HxB2 and 1153-1179 in SMM239) was employed for PCR. The NGS protocol to amplify and sequence the 300 competitions using 454 and MiSeq has been recently described. It is important to stress that the same results $(+/-2 \%$ variance) was observed with both NGS platforms despite the increased error rates with 454 . The alignments and analysis pipeline described below "count" the number of reads that cluster with one versus the other lentiviruses in 
the competition. All quasispecies of lentiviruses are genetically distinct using this amplified and sequenced gag or env region.

\section{Competition Sequence Data extraction and Analyses}

Sequence data was extracted and analyzed using SeekDeep, a software suit that enables de novo clustering thereby avoiding potential artifacts that may occur due to alignment directly to reference sequences in situations of divergent sequence populations. It provides start-to-finish workflow from raw sequences files to population-level clustering, tabular and graphical summaries(62). The program has three components namely: extractor, qluster and process Clusters.

Sequence reads were first separated at the sample level based on their MIDs/bar codes followed by the detection and removal of forward and reverse PCR primers to leave the targeted region. Additional filtering was performed to ensure expected target length and to remove low quality reads as indicated by low quality or ambiguous $(\mathrm{N})$ bases in the sequences. Next, was the clustering phase which involved the collapsing of unique reads except for high quality differences. Clusters that were up to 2 bases different from a more abundant haplotype were collapsed. Clusters composed of a single read were removed. During the SeekDeep process clustering phase, a final filtering was performed to remove low abundance artifacts and chimeric haplotypes, determined as a haplotype that was a combination of two other more abundant haplotype clusters ( $>2$-fold relative to potential chimera), low frequency chimeric haplotypes that represented combinations of and low abundance artifacts. These final haplotype clusters were than mapped to known input strain sequences allowing up to 5 mismatches and renamed appropriately. The relative abundance of the strains in each competition was then calculated and interactive graphs of the results were created to assess quality and view the data(62).

\section{Phylogenetic and Evolutionary analysis by Maximum Likelihood method}


All group $\mathrm{M}$ and $\mathrm{O}$ strains used in the study had been partially sequenced in the env gene (C2-V3; 480 nucleotides) and gag (MA p17; 350 nucleotides) as described previously (Abraha et al 2009). The group $\mathrm{N}$ and some of the SIV strains are available as full or partial genome sequences in the HIV Los Alamos database. Sequences were aligned using Clustal $X$ incorporated in the MEGA software. Reference sequences of various HIV types and groups were also included. The evolutionary history was inferred by using the Maximum Likelihood method and Kimura 2-parameter model(75). Initial tree(s) for the heuristic search were obtained automatically by applying Neighbor-Joining and BioNJ algorithms to a matrix of pairwise distances estimated using the Maximum Composite Likelihood (MCL) approach, and then selecting the topology with superior log likelihood value. The tree was drawn to scale, with branch lengths measured in the number of substitutions per site. Evolutionary analyses were conducted in MEGA $X(76)$.

\section{SiRNA inhibition of restriction factors}

U87-CCR5 cells were seeded with $5 \times 10^{4}$ per well in DMEM and incubated in 48 well plates overnight at $37^{\circ} \mathrm{C}$. On the next day, cells were washed with PBS and DMEM media replaced with 210ul of Opti-MEM (Thermofisher). siRNA against Trim $5 \alpha$, APOBEG 3F and G, and Tetherin obtained from Santa Cruz Biotechnology Inc. was dissolved respectively and resuspended in an accompanying diluent. Cells were then transfected with siRNA (10nM final concentration) using Lipofectamin RNAi Max reagent (Invitrogen) as follows: 0.6ul Lipofectamin in 20ul Opti-MEM and $0.25 \mathrm{ul}$ of the respective siRNA in 20ul Opti-MEM as described previously(77). These were then mixed and added drop wise in each well and incubated for $36 \mathrm{hrs}$. Cells were then washed with PBS, diluted virus added at a $\mathrm{MOI}$ of 0.001 and incubated at $37^{\circ} \mathrm{C}$ for $5 \mathrm{hrs}$ in DMEM. Cells were washed and resuspended in 400ul DMEM and supernatants were harvested on days 3, 5, 7 and 9 post infection and tested for RT activity. All experiments were done in triplicates; and included virus+scrambled siRNA, virus+siRNA, as well as negative controls (siRNA alone and cells alone). 
Endogenous expression of these restriction factors is rarely detected by Western blots using antibodies. The reduction of the restriction factor mRNA levels with these optimized siRNA was between $65-95 \%$. Please note the same U87 cell culture treated with one specific siRNA was split and utilized for infections with all lentiviruses.

\section{Statistical analyses}

We employed the spearman correlation to determine if there was any relationship between the genetic distance and the fitness in human PBMC, as well as fitness and CD4 ${ }^{+} \mathrm{T}$-cell depletion in the tonsil by the isolates. 
Acknowledgements: We thank Drs. Beatrice Hahn, Jonathan Heeney, and Brandon Keele for providing primate lentiviruses for this study. Support for this study to E.J.A. was provided by the NIH/NIAID R01 AI49170 and CIHR project grant 385787. Infrastructure support was provided by the NIH CFAR AI36219 and Canadian CFI/Ontario ORF 36287. Efforts of J.A.B. and N.J.H. was provided by NIH Al099473 for and Al099473. D.H.C. was funded by VA and NIH AI Al080313 for this study.

Competing interests: None of the authors have competing financial interest related to this study. 


\section{References}

1. Hemelaar J. The origin and diversity of the HIV-1 pandemic. Trends Mol Med [Internet]. 2012 Mar [cited 2019 Nov 11];18(3):182-92. Available from:

http://www.ncbi.nlm.nih.gov/pubmed/22240486

2. Tebit DM, Arts EJ. Tracking a century of global expansion and evolution of HIV to drive understanding and to combat disease. Lancet Infect Dis. 2011;11(1).

3. Hahn BH, Shaw GM, De Cock KM, Sharp PM. AIDS as a zoonosis: Scientific and public health implications. Vol. 287, Science. 2000. p. 607-14.

4. Peeters M, D'Arc M, Delaporte E. Origin and diversity of human retroviruses. Vol. 16, AIDS Reviews. 2014. p. 23-34.

5. Keele BF, Van HF, Li Y, Bailes E, Takehisa J, Santiago ML, Bibollet-Ruche F, Chen Y, Wain L V, Liegeois F, Loul S, Mpoudi NE, Bienvenue Y, Delaporte E, Brookfield JF, Sharp PM, Shaw GM, Peeters M, Hahn BH. Chimpanzee Reservoirs of Pandemic and Nonpandemic HIV-1. Science (80- ) [Internet]. 2006; Available from:

http://www.ncbi.nlm.nih.gov/pubmed/16728595

6. Van Heuverswyn F, Li Y, Neel C, Bailes E, Keele BF, Liu W, Loul S, Butel C, Liegeois F, Bienvenue Y, Ngolle EM, Sharp PM, Shaw GM, Delaporte E, Hahn BH, Peeters M. Human immunodeficiency viruses: SIV infection in wild gorillas. Nature. 2006 Nov 10;444(7116):164.

7. Gao F, Bailes E, Robertson DL, Chen Y, Rodenburg CM, Michael SF, Cummins LB, Arthur LO, Peeters M, Shaw GM, Sharp PM, Hahn BH. Origin of HIV-1 in the chimpanzee Pan troglodytes troglodytes [see comments]. Nature [Internet]. 1999;397(6718):436-41. Available from: http://www.ncbi.nlm.nih.gov/pubmed/0009989410

8. Gottlieb GS, Raugi DN, Smith RA. 90-90-90 for HIV-2? Ending the HIV-2 epidemic by enhancing care and clinical management of patients infected with HIV-2. Vol. 5, The Lancet HIV. Elsevier Ltd; 2018. p. e390-9.

9. Simon F, Mauclere P, Roques P, Loussert-Ajaka I, Muller-Trutwin MC, Saragosti S, Georges-Courbot MC, Barre-Sinoussi F, Brun-Vezinet F. Identification of a new human immunodeficiency virus type 1 distinct from group $\mathrm{M}$ and group O. NatMed [Internet]. 1998;4(9):1032-7. Available from: http://www.ncbi.nlm.nih.gov/pubmed/0009734396

10. Gürtler LG, Hauser PH, Eberle J, von Brunn A, Knapp S, Zekeng L, Tsague JM, Kaptue L. A new subtype of human immunodeficiency virus type 1 (MVP-5180) from Cameroon. J Virol. 1994;68(3):1581-5.

11. Vallari A, Holzmayer V, Harris B, Yamaguchi J, Ngansop C, Makamche F, Mbanya D, Kaptue L, Ndembi N, Gurtler L, Devare S, Brennan CA. Confirmation of Putative HIV-1 Group P in Cameroon. J Virol [Internet]. 2011 Feb 1 [cited 2019 Nov 11];85(3):1403-7. Available from: http://jvi.asm.org/cgi/doi/10.1128/JVI.02005-10

12. Aghokeng AF, Liu W, Bibollet-Ruche F, Loul S, Mpoudi-Ngole E, Laurent C, Mwenda JM, Langat DK, Chege GK, McClure HM, Delaporte E, Shaw GM, Hahn BH, Peeters M. 
Widely varying SIV prevalence rates in naturally infected primate species from Cameroon. Virology [Internet]. 2006;345(1):174-89. Available from:

http://www.ncbi.nlm.nih.gov/pubmed/16257029

13. Leoz M, Feyertag F, Kfutwah A, Mauclère P, Lachenal G, Damond F, De Oliveira F, Lemée V, Simon F, Robertson DL, Plantier JC. The Two-Phase Emergence of Non Pandemic HIV-1 Group O in Cameroon. PLoS Pathog. 2015 Aug 1;11(8).

14. VandeWoude S, Apetrei C. Going wild: Lessons from naturally occurring T-lymphotropic lentiviruses. Vol. 19, Clinical Microbiology Reviews. 2006. p. 728-62.

15. Van HF, Li Y, Neel C, Bailes E, Keele BF, Liu W, Loul S, Butel C, Liegeois F, Bienvenue Y, Ngolle EM, Sharp PM, Shaw GM, Delaporte E, Hahn BH, Peeters M. Human immunodeficiency viruses: SIV infection in wild gorillas. Nature [Internet]. 2006;444(7116):164. Available from: http://www.ncbi.nlm.nih.gov/pubmed/17093443

16. D’Arc M, Ayouba A, Esteban A, Learn GH, Boué V, Liegeois F, Etienne L, Tagg N, Leendertz FH, Boesch C, Madinda NF, Robbins MM, Gray M, Cournil A, Ooms M, Letko $\mathrm{M}$, Simon VA, Sharp PM, Hahn BH et al. Origin of the HIV-1 group O epidemic in western lowland gorillas. Proc Natl Acad Sci U S A. 2015 Mar 17;112(11):E1343-52.

17. Clavel F, Mansinho K, Chamaret S, Guetard D, Favier V, Nina J, Santos-Ferreira MO, Champalimaud JL, Montagnier L. Human Immunodeficiency Virus Type 2 Infection Associated with AIDS in West Africa. N Engl J Med. 1987 May 7;316(19):1180-5.

18. Hirsch VM, Olmsted RA, Murphey-Corb M, Purcell RH, Johnson PR. An African primate lentivirus (SIVsmm) closely related to HIV-2. Nat. 1989;339:389-91.

19. Santiago ML, Range F, Keele BF, Li Y, Bailes E, Bibollet-Ruche F, Fruteau C, Noe R, Peeters M, Brookfield JF, Shaw GM, Sharp PM, Hahn BH. Simian immunodeficiency virus infection in free-ranging sooty mangabeys (Cercocebus atys atys) from the Tai Forest, Cote d'Ivoire: implications for the origin of epidemic human immunodeficiency virus type 2. J Virol [Internet]. 2005;79(19):12515-27. Available from:

http://www.ncbi.nlm.nih.gov/pubmed/16160179

20. 2004 JUNP on H (UNAIDS) and WHO (WHO). UNAIDS AIDS epidemic update 2006. Geneva, Switzerland; 2006.

21. Nerrienet E, Santiago ML, Foupouapouognigni $Y$, Bailes E, Mundy NI, Njinku B, Kfutwah A, Muller-Trutwin MC, Barre-Sinoussi F, Shaw GM, Sharp PM, Hahn BH, Ayouba A. Simian immunodeficiency virus infection in wild-caught chimpanzees from cameroon. $J$ Virol [Internet]. 2005;79(2):1312-9. Available from:

http://www.ncbi.nlm.nih.gov/pubmed/15613358

22. Sharp PM, Hahn BH. Origins of HIV and the AIDS pandemic. Cold Spring HarbPerspectMed [Internet]. 2011;1(1):a006841. Available from:

http://www.ncbi.nlm.nih.gov/pubmed/22229120

23. Paraskevis D, Lemey P, Salemi M, Suchard M, Van De PY, Vandamme AM. Analysis of the evolutionary relationships of HIV-1 and SIVcpz sequences using bayesian inference: implications for the origin of HIV-1. MolBiolEvol [Internet]. 2003;20(12):1986-96. 
Available from: http://www.ncbi.nlm.nih.gov/pubmed/12949143

24. Li Y, Ndjango J-B, Learn GH, Ramirez MA, Keele BF, Bibollet-Ruche F, Liu W, Easlick JL, Decker JM, Rudicell RS, Inogwabini B-I, Ahuka-Mundeke S, Leendertz FH, Reynolds V, Muller MN, Chancellor RL, Rundus AS, Simmons N, Worobey M et al. Eastern Chimpanzees, but Not Bonobos, Represent a Simian Immunodeficiency Virus Reservoir. J Virol [Internet]. 2012 Oct 1 [cited 2019 Nov 11];86(19):10776-91. Available from: http://jvi.asm.org/cgi/doi/10.1128/JVI.01498-12

25. Switzer WM, Parekh B, Shanmugam V, Bhullar V, Phillips S, Ely JJ, Heneine W. The epidemiology of simian immunodeficiency virus infection in a large number of wild- and captive-born chimpanzees: Evidence for a recent introduction following chimpanzee divergence. AIDS Res Hum Retroviruses. 2005 May;21(5):335-42.

26. Corbet S, Muller-Trutwin MC, Versmisse P, Delarue S, Ayouba A, Lewis J, Brunak S, Martin P, Brun-Vezinet F, Simon F, Barre-Sinoussi F, Mauclere P. env sequences of simian immunodeficiency viruses from chimpanzees in Cameroon are strongly related to those of human immunodeficiency virus group $\mathrm{N}$ from the same geographic area. JVirol [Internet]. 2000;74(1):529-34. Available from:

http://www.ncbi.nlm.nih.gov/pubmed/0010590144

27. Prince AM, Brotman B, Lee DH, Andrus L, Valinsky J, Marx P. Lack of evidence for HIV type 1-related SIVcpz infection in captive and wild chimpanzees (Pan troglodytes verus) in West Africa. AIDS Res Hum Retroviruses. 2002;18(9):657-60.

28. Tebit DM, Arts EJ. From Simian to Human Immunodeficiency Viruses (SIV to HIV): Emergence from Nonhuman Primates and Transmission to Humans. In: The Role of Animals in Emerging Viral Diseases. Elsevier Inc.; 2013. p. 201-34.

29. Sauter D, Kirchhoff F. Key Viral Adaptations Preceding the AIDS Pandemic. Vol. 25, Cell Host and Microbe. Cell Press; 2019. p. 27-38.

30. Chesney MA, Ickovics JR, Chambers DB, Gifford AL, Neidig J, Zwickl B, Wu AW. Selfreported adherence to antiretroviral medications among participants in HIV clinical trials: the AACTG adherence instruments. Patient Care Committee \& Adherence Working Group of the Outcomes Committee of the Adult AIDS Clinical Trials Group (AACTG). AIDS Care [Internet]. 2000;12(3):255-66. Available from: http://www.ncbi.nlm.nih.gov/pubmed/10928201

31. Liégeois F, Schmidt F, Boué V, Butel C, Mouacha F, Ngari P, Ondo BM, Leroy E, Heeney JL, Delaporte E, Peeters M, Rouet F. Full-length genome analyses of two new simian immunodeficiency virus (SIV) strains from mustached monkeys (C. Cephus) in gabon illustrate a complex evolutionary history among the SIVmus/mon/gsn lineage. Viruses. 2014 Jul 22;6(7):2880-98.

32. Jin MJ, Hui H, Robertson DL, Muller MC, Barre-Sinoussi F, Hirsch VM, Allan JS, Shaw GM, Sharp PM, Hahn BH. Mosaic genome structure of simian immunodeficiency virus from west African green monkeys. EMBO J [Internet]. 1994;13(12):2935-47. Available from: http://www.ncbi.nlm.nih.gov/pubmed/8026477

33. Aghokeng AF, Bailes E, Loul S, Courgnaud V, Mpoudi-Ngolle E, Sharp PM, Delaporte E, 
Peeters M. Full-length sequence analysis of SIVmus in wild populations of mustached monkeys (Cercopithecus cephus) from Cameroon provides evidence for two cocirculating SIVmus lineages. Virology. 2007 Apr 10;360(2):407-18.

34. Courgnaud V, Abela B, Pourrut X, Mpoudi-Ngole E, Loul S, Delaporte E, Peeters M. Identification of a new simian immunodeficiency virus lineage with a vpu gene present among different cercopithecus monkeys (C. mona, C. cephus, and C. nictitans) from Cameroon. J Virol [Internet]. 2003;77(23):12523-34. Available from:

http://www.ncbi.nlm.nih.gov/pubmed/14610175

35. Bailes E, Gao F, Bibollet-Ruche F, Courgnaud V, Peeters M, Marx PA, Hahn BH, Sharp PM. Hybrid origin of SIV in chimpanzees. Science (80- ). 2003 Jun 13;300(5626):1713.

36. Hemelaar J, Elangovan R, Yun J, Dickson-Tetteh L, Fleminger I, Kirtley S, Williams B, Gouws-Williams E, Ghys PD, Abimiku AG, Agwale S, Archibald C, Avidor B, Barbás MG, Barre-Sinoussi F, Barugahare B, Belabbes EH, Bertagnolio S, Birx D et al. Global and regional molecular epidemiology of HIV-1, 1990-2015: a systematic review, global survey, and trend analysis. Lancet Infect Dis. 2019 Feb 1;19(2):143-55.

37. Venner CM, Nankya I, Kyeyune F, Demers K, Kwok C, Chen P-L, Rwambuya S, Munjoma M, Chipato T, Byamugisha J, Van Der Pol B, Mugyenyi P, Salata RA, Morrison CS, Arts EJ. Infecting HIV-1 Subtype Predicts Disease Progression in Women of SubSaharan Africa. EBioMedicine [Internet]. 2016 Nov [cited 2018 Apr 19];13:305-14. Available from: http://linkinghub.elsevier.com/retrieve/pii/S2352396416304698

38. Arien KK, Abraha A, Qui?ones-Mateu ME, Kestens L, Vanham G, Arts EJ. The replicative fitness of primary human immunodeficiency virus type 1 (HIV-1) group M, HIV-1 group O, and HIV-2 isolates. J Virol. 2005;79(14).

39. Arien KK, Vanham G, Arts EJ. Is HIV-1 evolving to a less virulent form in humans? NatRevMicrobiol [Internet]. 2007;5(2):141-51. Available from:

http://www.ncbi.nlm.nih.gov/pubmed/17203103

40. Kaleebu P, Ross A, Morgan D, Yirrell D, Oram J, Rutebemberwa A, Lyagoba F, Hamilton L, Biryahwaho B, Whitworth J. Relationship between HIV-1 Env subtypes A and D and disease progression in a rural Ugandan cohort. AIDS [Internet]. 2001;15(3):293-9. Available from: http://www.ncbi.nlm.nih.gov/pubmed/11273208

41. Neilson JR, John GC, Carr JK, Lewis P, Kreiss JK, Jackson S, Nduati RW, Mbori-Ngacha D, Panteleeff DD, Bodrug S, Giachetti C, Bott MA, Richardson BA, Bwayo J, NdinyaAchola J, Overbaugh J. Subtypes of human immunodeficiency virus type 1 and disease stage among women in Nairobi, Kenya. JVirol [Internet]. 1999;73(5):4393-403. Available from: http://www.ncbi.nlm.nih.gov/pubmed/0010196337

42. Abraha A, Nankya IL, Gibson R, Demers K, Tebit DM, Johnston E, Katzenstein D, Siddiqui A, Herrera C, Fischetti L, Shattock RJ, Arts EJ. CCR5- and CXCR4-Tropic Subtype C Human Immunodeficiency Virus Type 1 Isolates Have a Lower Level of Pathogenic Fitness than Other Dominant Group M Subtypes: Implications for the Epidemic. J Virol [Internet]. 2009 Jun 1 [cited 2017 Feb 28];83(11):5592-605. Available from: http://jvi.asm.org/cgi/doi/10.1128/JVI.02051-08 
43. Rubio AE, Abraha A, Carpenter CA, Troyer RM, Reyes-Rodríguez ÁL, Salomon H, Arts EJ, Tebit DM. Similar replicative fitness is shared by the subtype B and unique BF recombinant HIV-1 isolates that dominate the epidemic in Argentina. Vartanian J-P, editor. PLoS One [Internet]. 2014 Apr 11 [cited 2018 Apr 19];9(4):e92084. Available from: http://dx.plos.org/10.1371/journal.pone.0092084

44. Quinones-Mateu ME, Ball SC, Marozsan AJ, Torre VS, Albright JL, Vanham G, Van Der Groen G, Colebunders RL, Arts EJ. A dual infection/competition assay shows a correlation between Ex vivo human immunodeficiency virus type 1 fitness and disease progression. J Virol. 2000;74(19).

45. Troyer RM, Collins KR, Abraha A, Fraundorf E, Moore DM, Krizan RW, Toossi Z, Colebunders RL, Jensen MA, Mullins JI, Vanham G, Arts EJ. Changes in human immunodeficiency virus type 1 fitness and genetic diversity during disease progression. $\mathrm{J}$ Virol. 2005;79(14).

46. Hartung S, Boller K, Cichutek K, Norley SG, Kurth R. Quantitation of a lentivirus in its natural host: simian immunodeficiency virus in African green monkeys. J Virol [Internet]. 1992 Apr [cited 2019 Nov 11];66(4):2143-9. Available from:

http://www.ncbi.nlm.nih.gov/pubmed/1548755

47. Pandrea I, Ribeiro RM, Gautam R, Gaufin T, Pattison M, Barnes M, Monjure C, Stoulig C, Dufour J, Cyprian W, Silvestri G, Miller MD, Perelson AS, Apetrei C. Simian Immunodeficiency Virus SIVagm Dynamics in African Green Monkeys. J Virol [Internet]. 2008 Apr 1 [cited 2019 Nov 11];82(7):3713-24. Available from:

http://jvi.asm.org/cgi/doi/10.1128/JVI.02402-07

48. Ondoa P, Kestens L, Davis D, Vereecken C, Willems B, Fransen K, Vingerhoets J, Zissis G, Haaft P Ten, Heeney J, Van Groen G Der. Longitudinal comparison of virus load parameters and CD8 T-cell suppressive capacity in two SIVcpz-infected chimpanzees. J Med Primatol. 2001;30(5):243-53.

49. Hirsch VM. What can natural infection of African monkeys with simian immunodeficiency virus tell us about the pathogenesis of AIDS? AIDS Rev [Internet]. [cited 2019 Nov 11];6(1):40-53. Available from: http://www.ncbi.nlm.nih.gov/pubmed/15168740

50. Keele BF, Jones JH, Terio KA, Estes JD, Rudicell RS, Wilson ML, Li Y, Learn GH, Beasley TM, Schumacher-Stankey J, Wroblewski E, Mosser A, Raphael J, Kamenya S, Lonsdorf E V., Travis DA, Mlengeya T, Kinsel MJ, Else JG et al. Increased mortality and AIDS-like immunopathology in wild chimpanzees infected with SIVcpz. Nature. 2009 Jul 23;460(7254):515-9.

51. Azevedo-Pereira JM, Santos-Costa Q. HIV interaction with human host: HIV-2 As a model of a less virulent infection. Vol. 18, AIDS Reviews. Publicaciones Permanyer; 2016. p. 44-53.

52. Whittle H, Morris J, Todd J, Corrah T, Sabally S, Bangali J, Ngom PT, Rolfe M, Wilkins A. HIV-2-infected patients survive longer than HIV-1-infected patients. AIDS. 1994;8(11):1617-20.

53. Grivel J-C, Malkevitch N, Margolis L. Human Immunodeficiency Virus Type 1 Induces 
Apoptosis in CD4+ but Not in CD8+ T Cells in Ex Vivo-Infected Human Lymphoid Tissue. J Virol. 2000 Sep 1;74(17):8077-84.

54. Geuenich S, Kaderali L, Allespach I, Sertel S, Keppler OT. Biological Signature Characteristics of Primary Isolates from Human Immunodeficiency Virus Type 1 Group 0 in Ex Vivo Human Tonsil Histocultures. J Virol. 2009 Oct 15;83(20):10494-503.

55. Arien KK, Abraha A, Quinones-Mateu ME, Kestens L, Vanham G, Arts EJ. The replicative fitness of primary human immunodeficiency virus type 1 (HIV-1) group $\mathrm{M}, \mathrm{HIV}-1$ group $\mathrm{O}$, and HIV-2 isolates. JVirol [Internet]. 2005;79(14):8979-90. Available from:

http://www.ncbi.nlm.nih.gov/pubmed/15994792

56. Arts EJ, Qui?ones-Mateu ME. Sorting out the complexities of HIV-1 fitness [2]. AIDS. 2003;17(5).

57. Ball SC, Abraha A, Collins KR, Marozsan AJ, Baird H, Qui?ones-Mateu ME, PennNicholson A, Murray M, Richard N, Lobritz M, Zimmerman PA, Kawamura T, Blauvelt A, Arts EJ. Comparing the ex vivo fitness of CCR5-tropic human immunodeficiency virus type 1 isolates of subtypes B and C. J Virol. 2003;77(2).

58. Quinones-Mateu ME, Gao S.C. YB, Marozsan AJ, Abraha A, Arts EJ. In vitro intersubtype recombinants of human immunodeficiency virus type 1: comparison to recent and circulating in vivo recombinant forms. JVirol. 2002;76:In press.

59. Baird HA, Gao Y, Galetto R, Lalonde M, Anthony RM, Giacomoni V, Abreha M, Destefano JJ, Negroni M, Arts EJ. Influence of sequence identity and unique breakpoints on the frequency of intersubtype HIV-1 recombination. Retrovirology. 2006;3.

60. Rubio AE, Abraha A, Carpenter CA, Troyer RM, Reyes-Rodríguez ÁL, Salomon H, Arts EJ, Tebit DM. Similar replicative fitness is shared by the subtype $B$ and unique BF recombinant HIV-1 isolates that dominate the epidemic in Argentina. Vartanian J-P, editor. PLoS One [Internet]. 2014 Apr 11 [cited 2017 Feb 28];9(4):e92084. Available from: http://dx.plos.org/10.1371/journal.pone.0092084

61. Tebit DM, Lobritz M, Lalonde M, Immonen T, Singh K, Sarafianos S, Herchenr?der O, Kr? usslich H-G, Arts EJ. Divergent evolution in reverse transcriptase (RT) of HIV-1 group $\mathrm{O}$ and $\mathrm{M}$ lineages: Impact on structure, fitness, and sensitivity to nonnucleoside RT inhibitors. J Virol. 2010;84(19).

62. Hathaway NJ, Parobek CM, Juliano JJ, Bailey JA. SeekDeep: Single-base resolution de novo clustering for amplicon deep sequencing. Nucleic Acids Res. 2018 Feb 28;46(4).

63. Bush S, Tebit DM. HIV-1 group O origin, evolution, pathogenesis, and treatment: Unraveling the complexity of an outlier 25 years later. AIDS Rev. 2015;17(3):147-58.

64. Malim MH, Bieniasz PD. HIV Restriction Factors and Mechanisms of Evasion. Cold Spring Harb Perspect Med [Internet]. 2012 May [cited 2019 Nov 20];2(5):a006940. Available from: http://www.ncbi.nlm.nih.gov/pubmed/22553496

65. Eckstein DA, Penn ML, Korin YD, Scripture-Adams DD, Zack JA, Kreisberg JF, Roederer M, Sherman MP, Chin PS, Goldsmith MA. HIV-1 actively replicates in naive CD4+ T cells 
residing within human lymphoid tissues. Immunity. 2001;15(4):671-82.

66. Gifford RJ, Katzourakis A, Tristem M, Pybus OG, Winters M, Shafer RW. A transitional endogenous lentivirus from the genome of a basal primate and implications for lentivirus evolution. Proc Natl Acad Sci U S A. 2008 Dec 23;105(51):20362-7.

67. Wertheim JO, Worobey M. Dating the age of the SIV lineages that gave rise to HIV-1 and HIV-2. PLoS Comput Biol. 2009 May;5(5).

68. Lemey P, Pybus OG, Rambaut A, Drummond AJ, Robertson DL, Roques P, Worobey M, Vandamme AM. The molecular population genetics of HIV-1 group O. Genetics. 2004 Jul;167(3):1059-68.

69. Korber B, Muldoon M, Theiler J, Gao F, Gupta R, Lapedes A, Hahn BH, Wolinsky S, Bhattacharya T. Timing the ancestor of the HIV-1 pandemic strains. Science (80- ) [Internet]. 2000;288(5472):1789-96. Available from:

http://www.ncbi.nlm.nih.gov/pubmed/10846155

70. Arien KK, Troyer RM, Gali Y, Colebunders RL, Arts EJ, Vanham G. Replicative fitness of historical and recent HIV-1 isolates suggests HIV-1 attenuation over time. AIDS [Internet]. 2005;19(15):1555-64. Available from: http://www.ncbi.nlm.nih.gov/pubmed/16184024

71. Blaak $H$, van't Wout $A B$, Brouwer M, Hooibrink B, Hovenkamp E, Schuitemaker H. In vivo HIV-1 infection of CD45RA(+)CD4(+) T cells is established primarily by syncytiuminducing variants and correlates with the rate of CD4(+) T cell decline. ProcNatlAcadSciUSA [Internet]. 2000;97(3):1269-74. Available from: http://www.ncbi.nlm.nih.gov/pubmed/10655520

72. Marozsan AJ, Fraundorf E, Abraha A, Baird H, Moore D, Troyer R, Nankja I, Arts EJ. Relationships between infectious titer, capsid protein levels, and reverse transcriptase activities of diverse human immunodeficiency virus type 1 isolates. J Virol. 2004;78(20).

73. Reyes-Rodriguez AL, Reuter MA, McDonald D. Dendritic Cells Enhance HIV Infection of Memory CD4(+) T Cells in Human Lymphoid Tissues. AIDS Res Hum Retroviruses [Internet]. 2016 Feb [cited 2019 Nov 13];32(2):203-10. Available from: http://www.ncbi.nlm.nih.gov/pubmed/26651015

74. Tebit DM, Zekeng L, Kaptue L, Gurtler L, Fackler OT, Keppler OT, Herchenroder O, Krausslich HG. Construction and characterization of an HIV-1 group O infectious molecular clone and analysis of vpr- and nef-negative derivatives. Virology [Internet]. 2004;326(2):329-39. Available from: http://www.ncbi.nlm.nih.gov/pubmed/15321704

75. Kimura M. A simple method for estimating evolutionary rates of base substitutions through comparative studies of nucleotide sequences. JMolEvol [Internet]. 1980;16(2):111-20. Available from: http://www.ncbi.nlm.nih.gov/pubmed/7463489

76. Kumar S, Tamura K, Jakobsen IB, Nei M. MEGA2: molecular evolutionary genetics analysis software. Bioinformatics [Internet]. 2001;17(12):1244-5. Available from: http://www.ncbi.nlm.nih.gov/pubmed/11751241

77. Gao Y, Lobritz MA, Roth J, Abreha M, Nelson KN, Nankya I, Moore-Dudley DM, Abraha 
bioRxiv preprint doi: https://doi.org/10.1101/2020.10.13.337303; this version posted October 13,2020 . The copyright holder for this preprint (which was not certified by peer review) is the author/funder, who has granted bioRxiv a license to display the preprint in perpetuity. It is made available under aCC-BY 4.0 International license.

A, Gerson SL, Arts EJ. Targets of small interfering RNA restriction during human immunodeficiency virus type 1 replication. J Virol. 2008;82(6). 
bioRxiv preprint doi: https://doi.org/10.1101/2020.10.13.337303; this version posted October 13,2020. The copyright holder for this preprint (which was not certified by peer review) is the author/funder, who has granted bioRxiv a license to display the preprint in perpetuity. It is made

\section{A} available under aCC-BY 4.0 International license.

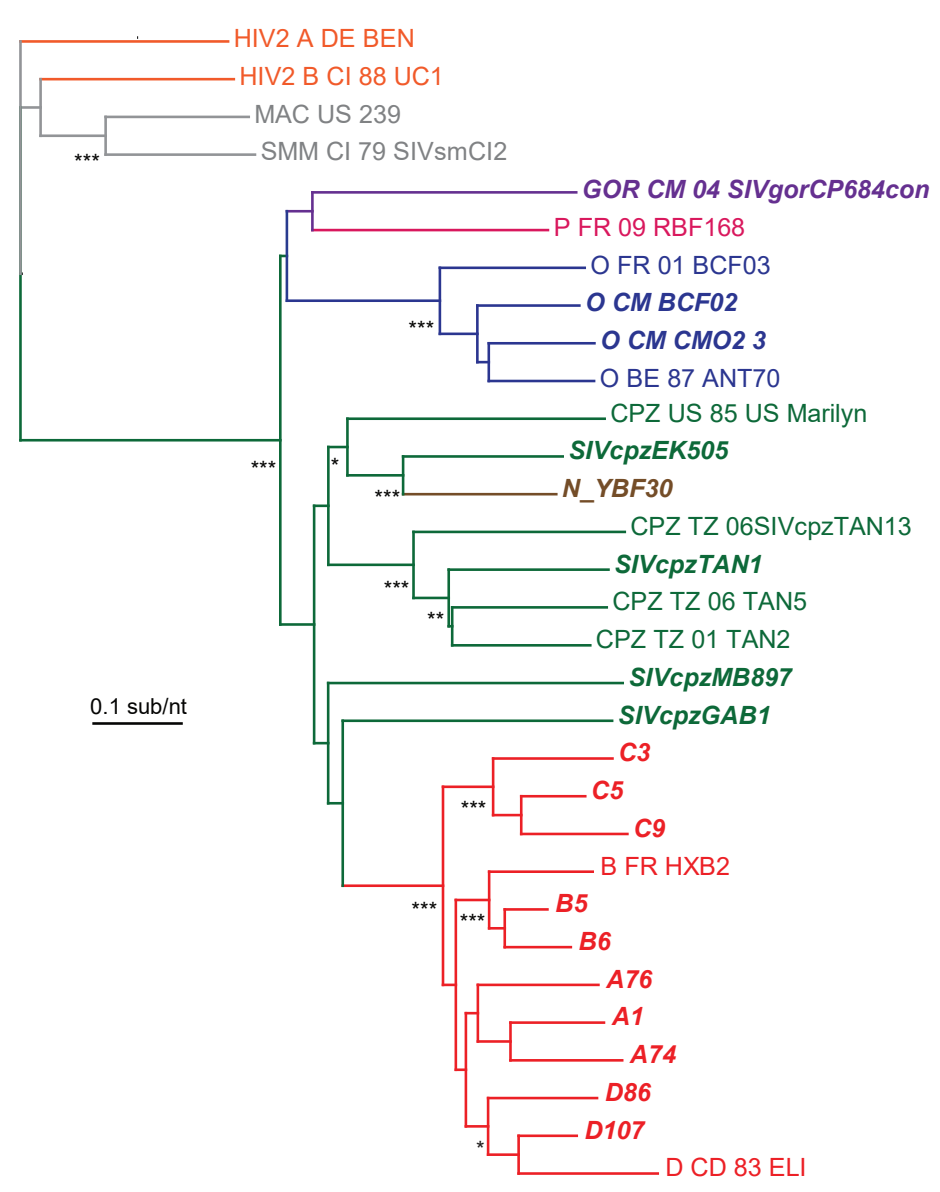

B 3 \begin{tabular}{llllcc} 
Reference & Virus name & $\begin{array}{l}\text { Country } \\
\text { of Origin }\end{array}$ & Type/group & $\begin{array}{c}\text { subtype } \\
\text { (gag/env) }\end{array}$ & $\begin{array}{c}\text { TCID50 } \\
\text { (IU/ml) }\end{array}$ \\
\hline A1 & 92 RW009 & Rwanda & HIV-1/M & C/A & 4.75
\end{tabular}

$\begin{array}{lllll}\text { A78 UG primary Uganda HIV-1/M } & \text { A/A } & 3.75\end{array}$

$\begin{array}{lllll}\text { A74 UG primary Uganda } & \text { HIV-1/M } & \text { A/A } & 5.75\end{array}$

$\begin{array}{lllll}\text { B5 91US056 USA HIV-1/M } & \text { B/B } & 5.25\end{array}$

$\begin{array}{llllll}\text { B6 } & \text { IUS714 USA } & \text { HIV-1/M } & \text { B/B } & 4.75\end{array}$

\begin{tabular}{|c|c|c|}
\hline 97ZA012 & S. Africa & HIV-1/M \\
\hline
\end{tabular}

$\begin{array}{llllll}\text { C5 } & 97 Z A 003 & \text { S. Africa } & \text { HIV }-1 / M & \text { C/C } & 5.5\end{array}$

$\begin{array}{lllll}\text { C9 } 93 M w 959 & \text { Malawi } & \text { HIV-1/M } & 4.75\end{array}$

D107 UG primary Uganda HIV-1/M D/D 5

$\begin{array}{lllll}\text { D76 UG primary Uganda HIV-1/M } & \text { D/D }\end{array}$

$\begin{array}{lllll}\text { CMO2-41 MVP8913 Cameroon } & \text { HIV-1/O } & \text { O/O } & 4.75\end{array}$

$\begin{array}{lllll}\mathrm{O} 2 & \mathrm{BCFO2} & \mathrm{H} 2 \mathrm{HIV}-1 / \mathrm{O} & \mathrm{O} / \mathrm{O} & 4.75\end{array}$

$\begin{array}{lllll} & \text { B13 HCF07 } & \text { Cameroon } & \text { HIV-1/O } & \text { O/O }\end{array}$

$\begin{array}{lllll}\text { YBF30 } & \text { YBF30 } & \text { Cameroon } & \text { HIV-1/N } & \text { N/N }\end{array}$

$\begin{array}{lllll}\text { EK505 } & \text { EK505 } & \text { Cameroon } & \text { SIVcpz-Ptt } & \text { NA }\end{array}$

$\begin{array}{lllll}\text { MB897-1 MB897-1 } & \text { Cameroon } & \text { SIVcpz-Ptt } & \text { NA } & 2.5\end{array}$

$\begin{array}{lllll}\text { Gab1 Gab1.1 } & \text { Gabon } & \text { SIVcpz-Ptt } & \text { NA }\end{array}$

$\begin{array}{lllll}\text { Nico Nico } & \text { ?? } & \text { SIVcpz-Pts } & \text { NA } & 2.5\end{array}$

$\begin{array}{lllll}\text { Noah Noah } & \text { ?? } & \text { SIVcpz-Pts } & \text { NA } & 2.75\end{array}$

$\begin{array}{lllll}\text { Tan3.1 Tan3.1 } \quad \text { SIVcpz-Pts } & \text { NA } & 1.5\end{array}$

$\begin{array}{lllll}\text { SIVgor } & \text { CP684 } & \text { Cameroon } & \text { SIVgor } & \text { NA }\end{array}$

$\begin{array}{lllll}\text { SIVagm } & \text { SIVagm } & \text { ?? } & \text { SIVagm } & \text { NA }\end{array}$

$\begin{array}{lllll}\text { SIVmac } & \text { SIVmac } & \text { ?? } & \text { SIVagm } & \text { NA }\end{array}$

$\begin{array}{lllll}\text { SIVsmm } & \text { SIVsmm } & \text { ?? } & \text { SIVsmm } & \text { NA }\end{array}$

$\begin{array}{lllll}\text { VI1835 VI1835 } & \text { Ivory Coast } & \text { HIV-2 } & \text { A/A } & 5.5\end{array}$

$\begin{array}{lllll}\text { VI905 VI905 } & \text { Senegal } & \text { HIV }-2 & \text { A/A } & 2.5\end{array}$

Figure 1: Characteristics of lentiviruses used in this study. (A) Neighbor joining phylogenetic tree of the env sequence of primate lentiviruses with reference strains. (B) List of study viruses showing origin, genotype, and virus titres (tissue culture infectious dose for $50 \%$ infectivity; $\operatorname{TCID}_{50}$ ). 

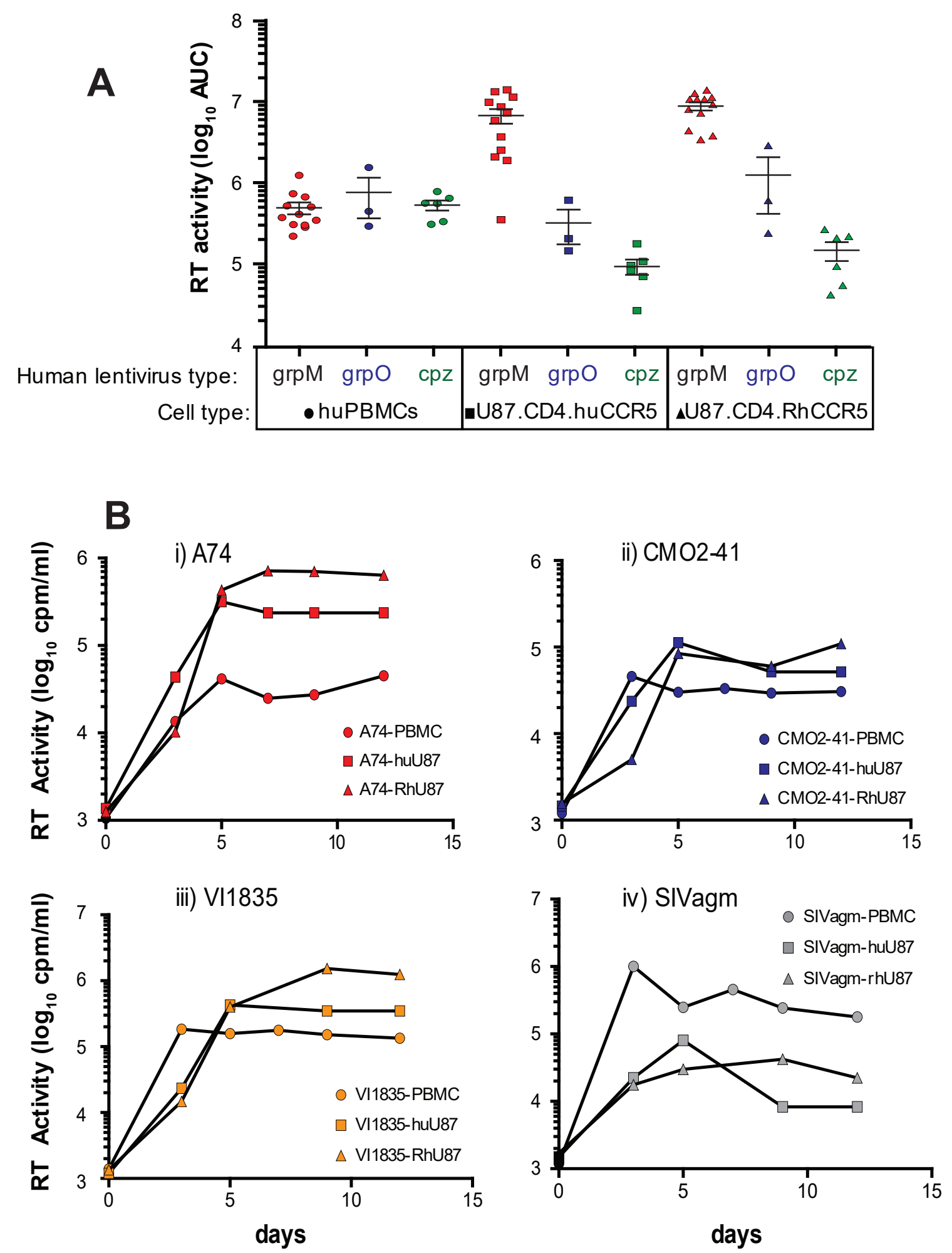

Figure 2: Replication of primate lentiviruses in human PBMCs or CD4+ U87 cells expressing human or rhesus macaque CCR5 as measured by reverse transcriptase activity in supernatant. Panel (A) shows area-under-the curve of virus production for HIV-1 group M, group O, and SIVcpz strains over a 12 day infection as measured by RT activity. Examples of individual production of group M A74 (i), group O CMO2-41 (ii), HIV-2 VI1835 (iii), and SIVagm (iv) is shown. All infections were done in triplicate. Standard deviations at each time point were within $20 \%$ of the value on average and are not shown. 
bioRxiv preprint doi: https://doi.org/10.1101/2020.10.13.337303; this version posted October 13, 2020. The copyright holder for this preprint (which was not certified by peer review) is the author/funder, who has granted bioRxiv a license to display the preprint in perpetuity. It is made available under aCC-BY 4.0 International license.

\section{A Schematic of dual virus competitions in human PBMCs (or chimp PBMCs)}
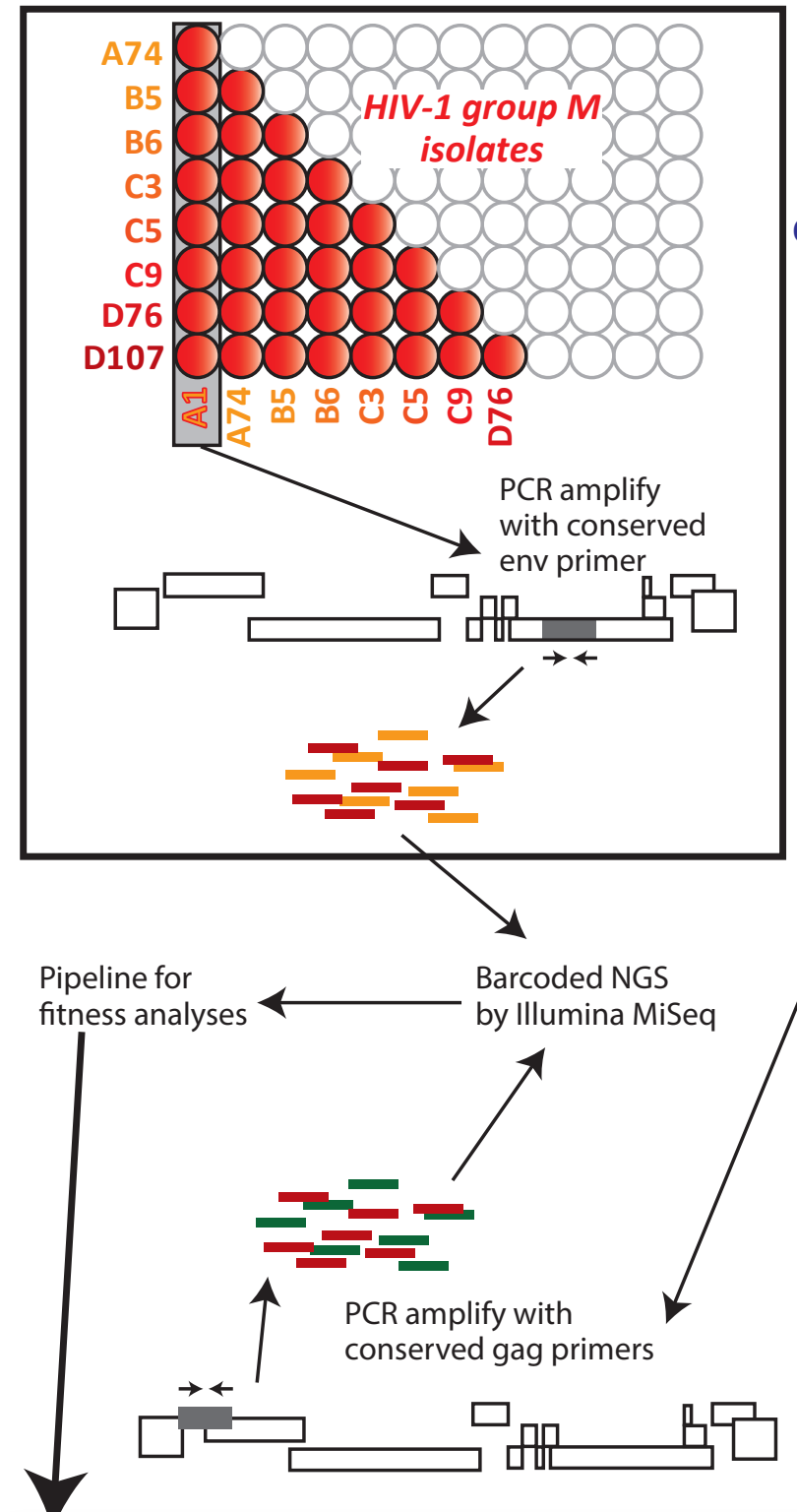
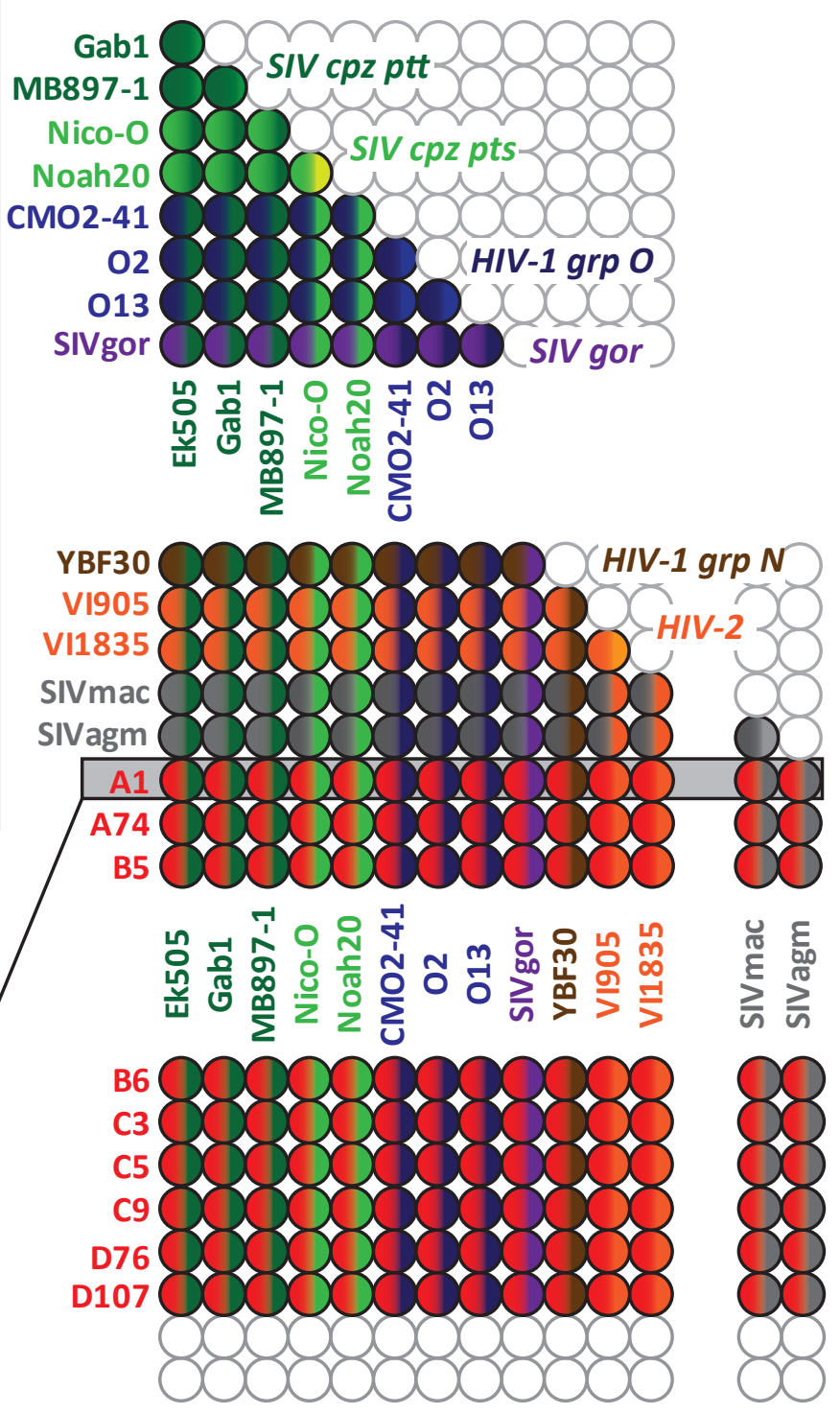

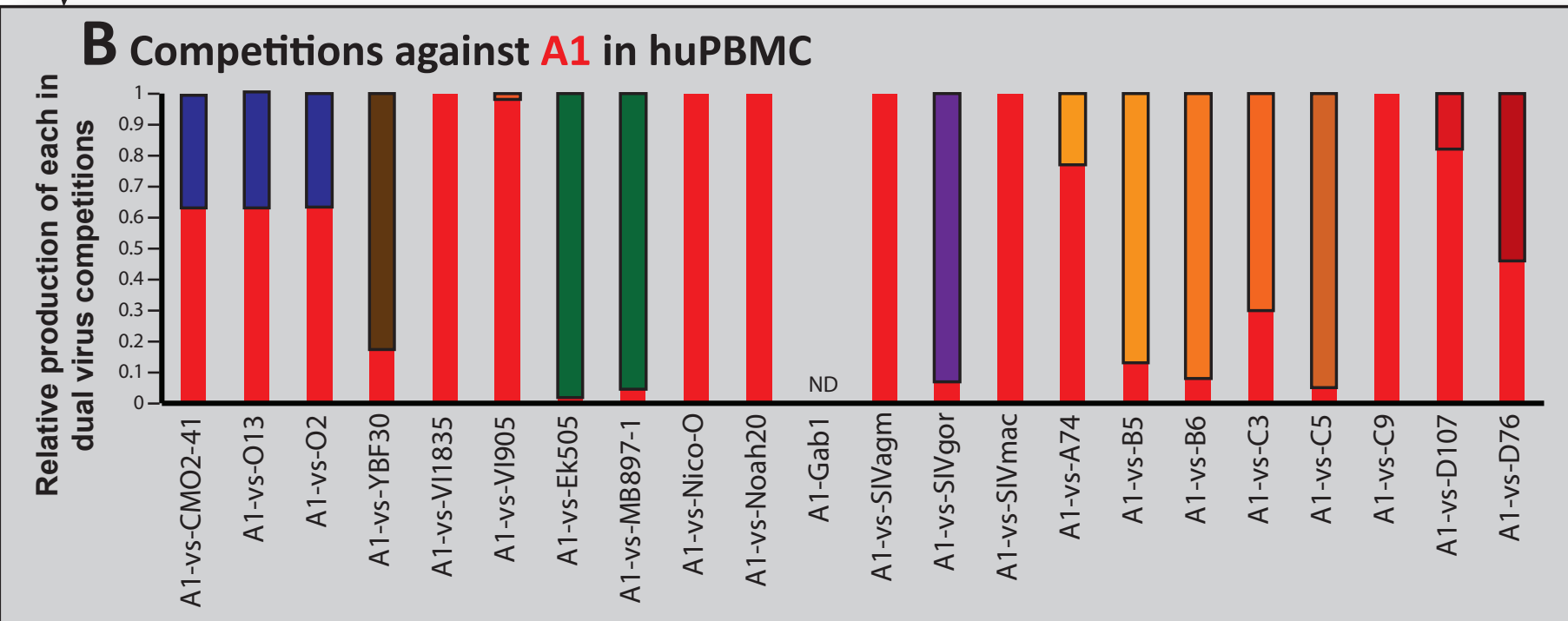

Figure 3: A) Schematic llustration of dual virus competitions in human and chimpanzee PBMC, (B) Results of the pairwise infections involving competitions of the HIV-1 group M A1 strain against all other primate lentiviruses. Relative production of both viruses as measure by NGS and SeekDeep is shown. 


\section{human PMBCs}

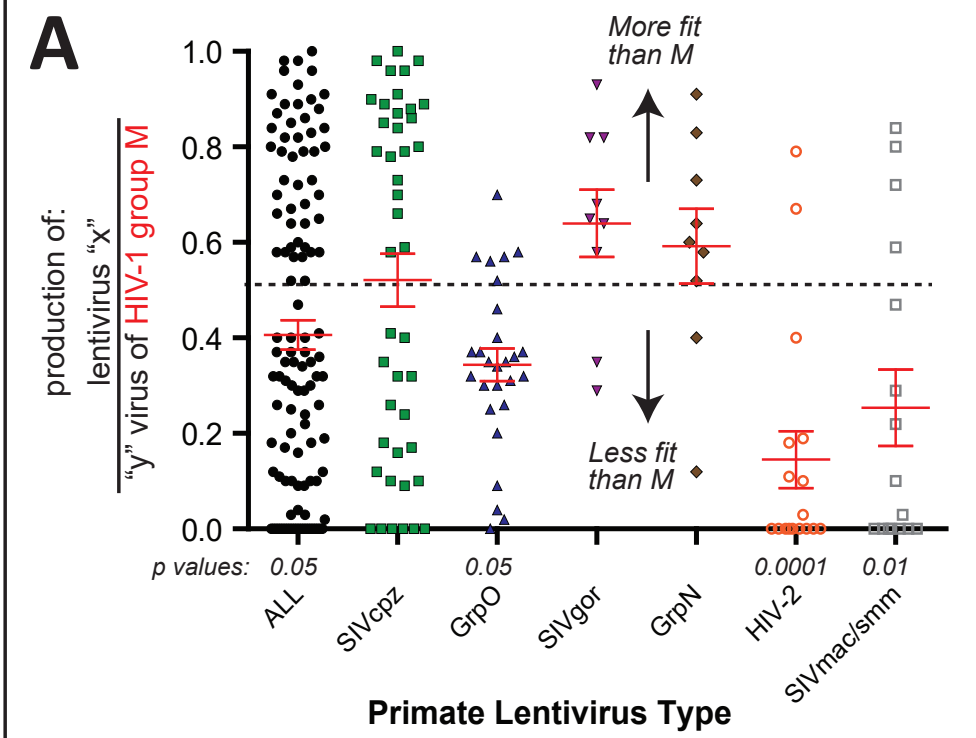

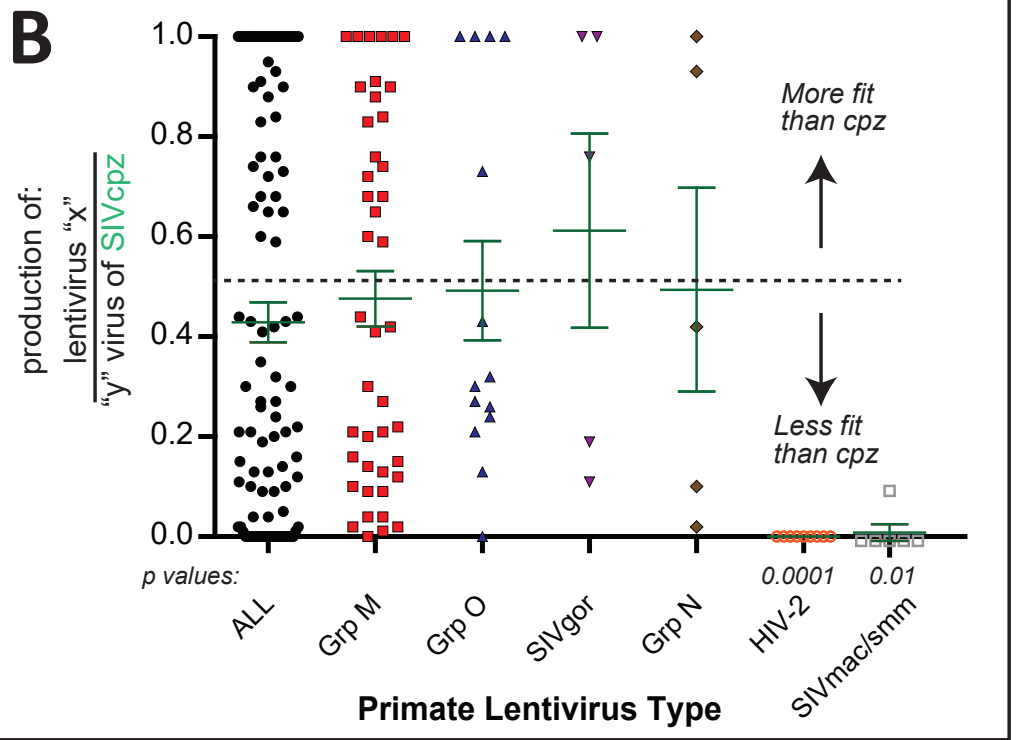

\section{chimpanzee PMBCs}
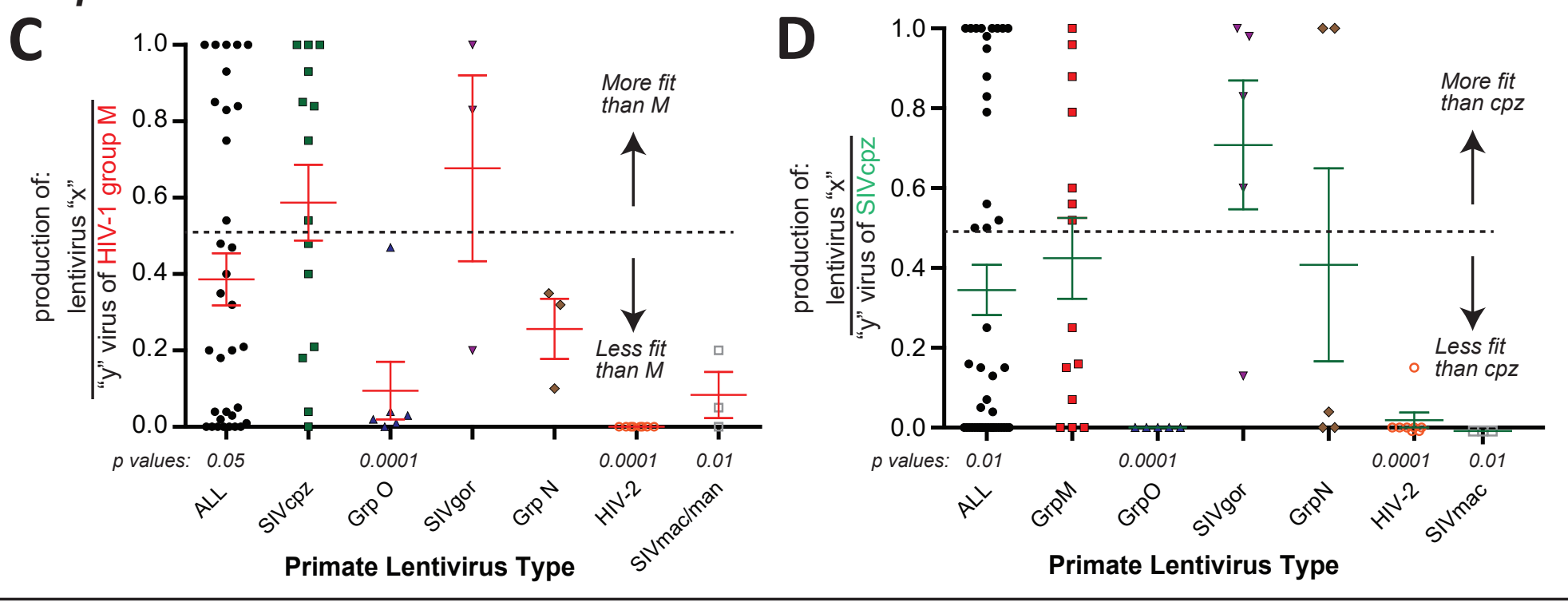

Figure 4: Fitness analyses of HIV-1, -2, and SIV isolates in human and chimpanzee PBMCs. As described in Figure 3, pairwise competitions were performed in human PBMCs and subset in chimpanzee PBMCs. The production from these dual virus competitions were PCR amplified, subject to NGS, and analyzed by SeekDeep to obtain the relative production of each virus in each dual virus competition. These values are plotted as the produciton of any lentivirus relative to the group $M(A$ and $C$ ) or SIVcpz (B and D) in HsPBMCs (A and B) or PtvPBMCs (C and D). E. For this comparison, the replicative fitness of members of one primate lentivirus group/type (e.g. HIV-1 group M) competed against members of all other groups/types was analyzed for an intergroup/type replicative fitness. This analyses excludes all of the intragroup/type dual virus competitions (e.g. HIV-1 group M A74 versus B5). The geometric mean and box of $95 \%$ of the relative fitness values with outlier whiskers is plotted for each group/type of primate lentivirus. Full statistical analyzes of all panels is provided in Supplementary tables 1 to 5 , respectively. 
bioRxiv preprint doi: https://doi.org/10.1101/2020.10.13.337303; this version posted October 13,2020 . The copyright holder for this preprint (which was not certified by peer review) is the author/funder, who has granted bioRxiv a license to display the preprint in perpetuity. It is made available under aCC-BY 4.0 International license.

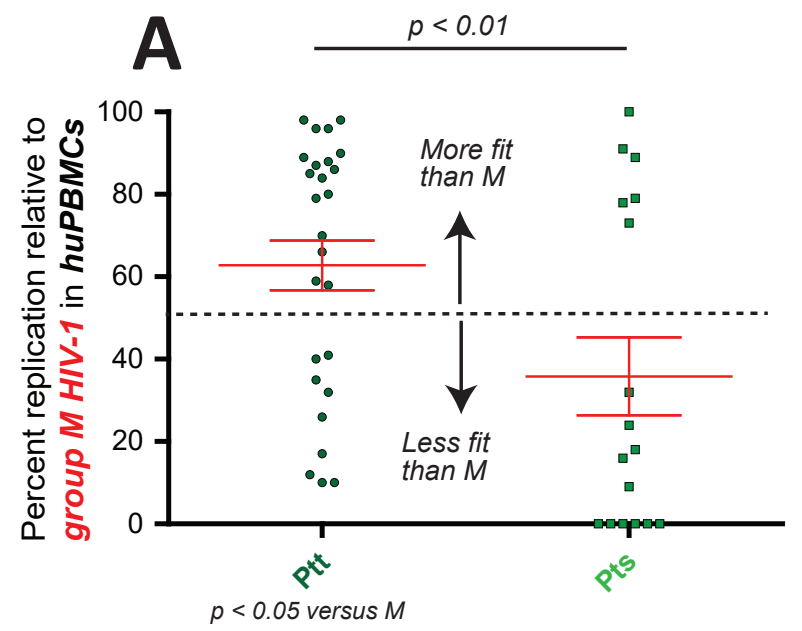

SIVcpz Type

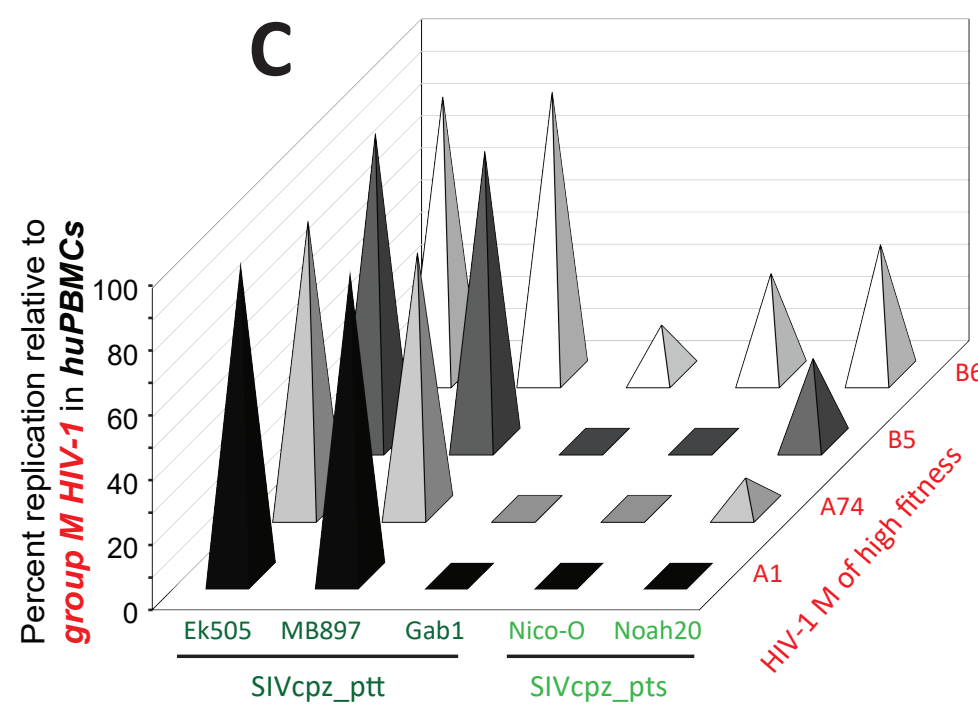

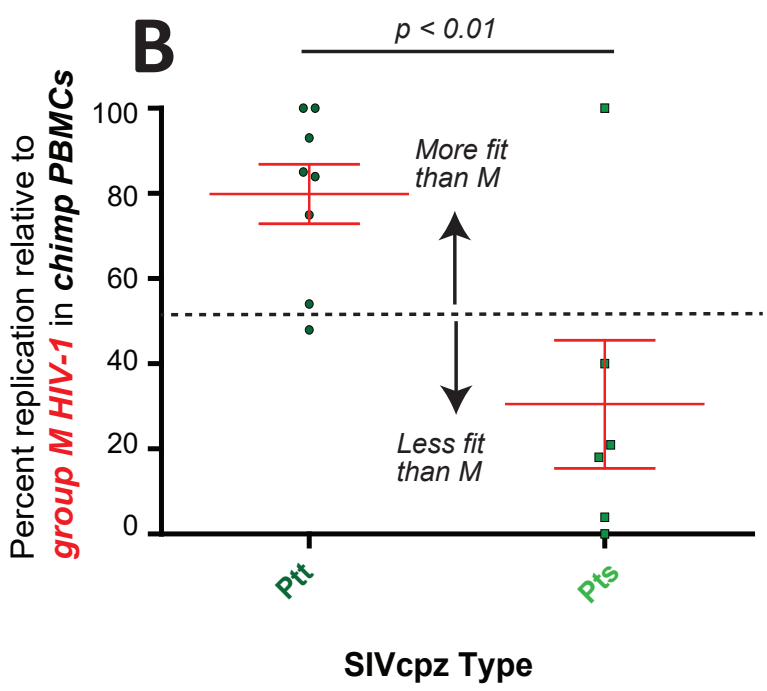

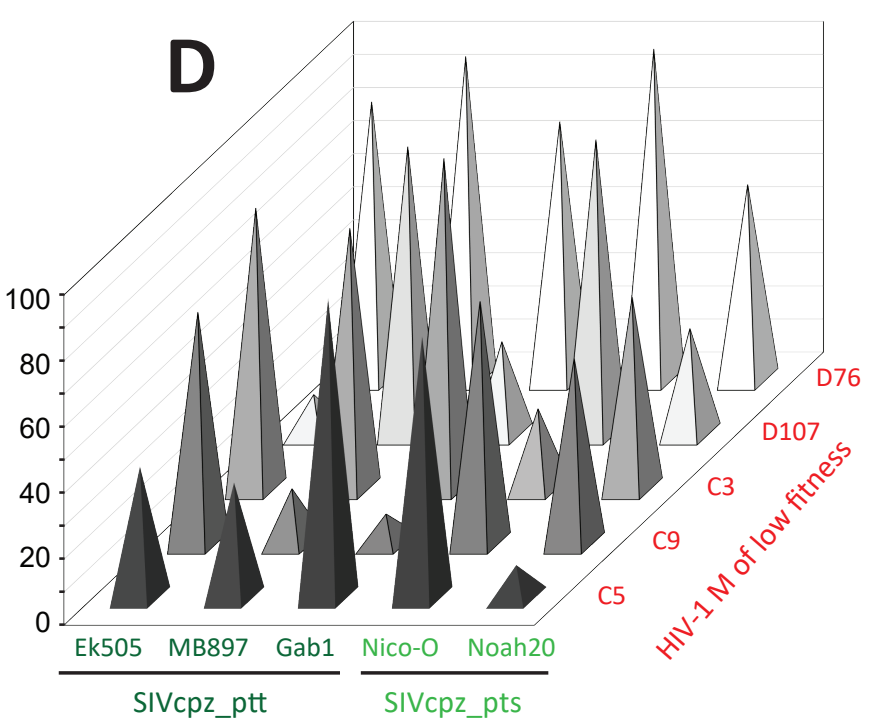

Figure 5: Fitness of various SIVcpz strains of Ptt and Pts competed against HIV-1 group M strains in A) HsPBMC and B) PtvPBMC. SIVcpz_ptt and_pts strains competed in human PBMCs against C) HIV-1 group M of high fitness and $D$ ) group $M$ of low fitness. 
bioRxiv preprint doi: https://doi.org/10.1101/2020.10.13.337303; this version posted October 13,2020 . The copyright holder for this preprint (which was not certified by peer review) is the author/funder, who has granted bioRxiv a license to display the preprint in perpetuity. It is made available under aCC-BY 4.0 International license.
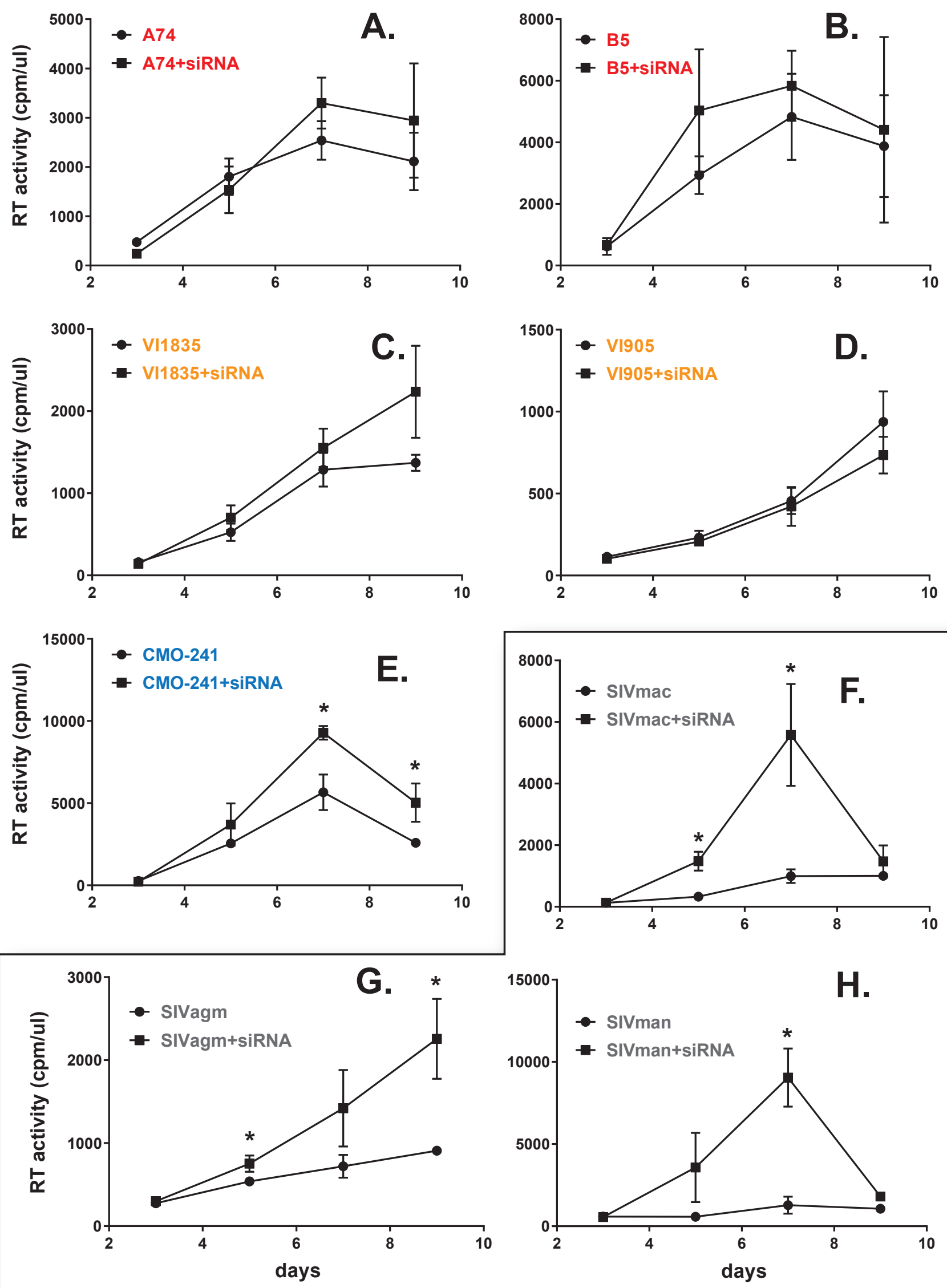

Figure 6. Primate lentivirus replication in human CD4+ U87 cells expressing HsCCR5 and pre-treated with siRNA to Tetherin/BST2. HIV-1 group M A74 (A), B5 (B), HIV-2 VI1835 (C), VI905 (D), HIV-1 group O CMO-241 $(E)$, and SIVmac $(F)$, agm $(G)$, and man $(H)$ were used to infected CD4/HsCCR5 U87 cells treated with scrambled siRNA or siRNA specific to mRNA Tetherin/BST2. All infections and treatments were performed in triplicate. ${ }^{*}$ represents $p<0.05$, multiple one-tailed $T$ tests. 

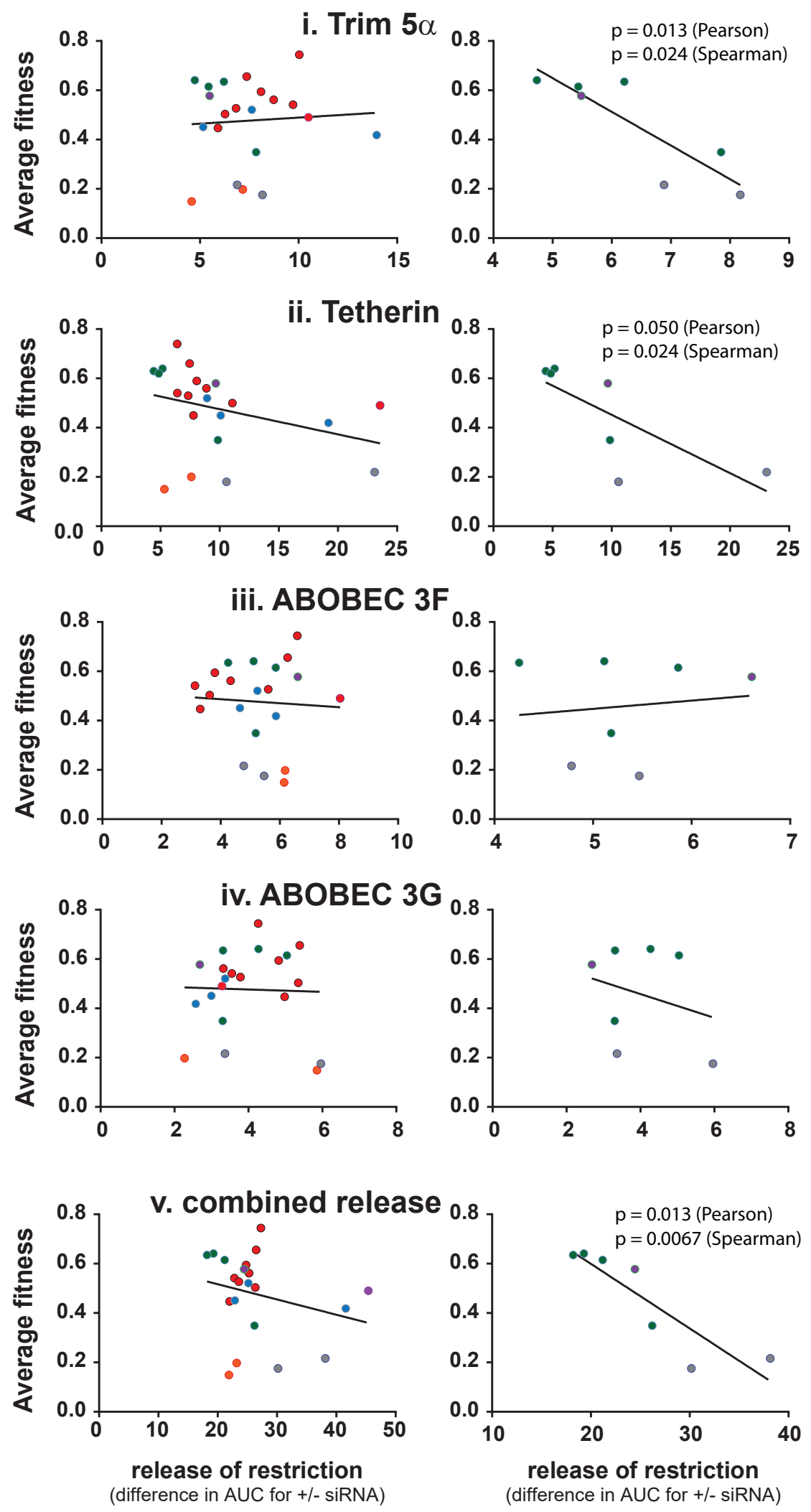

Figure 7: Comparing the average replicative fitness to the release of restriction (mediated by siRNAs). The average replicative fitness for each primate lentivirus was determined from the pairwise competitions in HsPBMCs as described in Supplementary Figure 3. Each primate lentivirus was also used to infect cells in the presence of a specific siRNA to restriction factor or a scrambled siRNA. The area under the curve for the 9 day infection with specific siRNA was subtracted from that with scrambled siRNA. (A) For each primate lentivurs, plots of average replicative fitness versus the relative release of replication due to Trim $5 a$ (i), Tetherin/BST2 (ii), ABOBEC 3G (iii), 3F (iv), and all four combined (v). (B) The same plots as in (A) but without the human lentiviruses. 

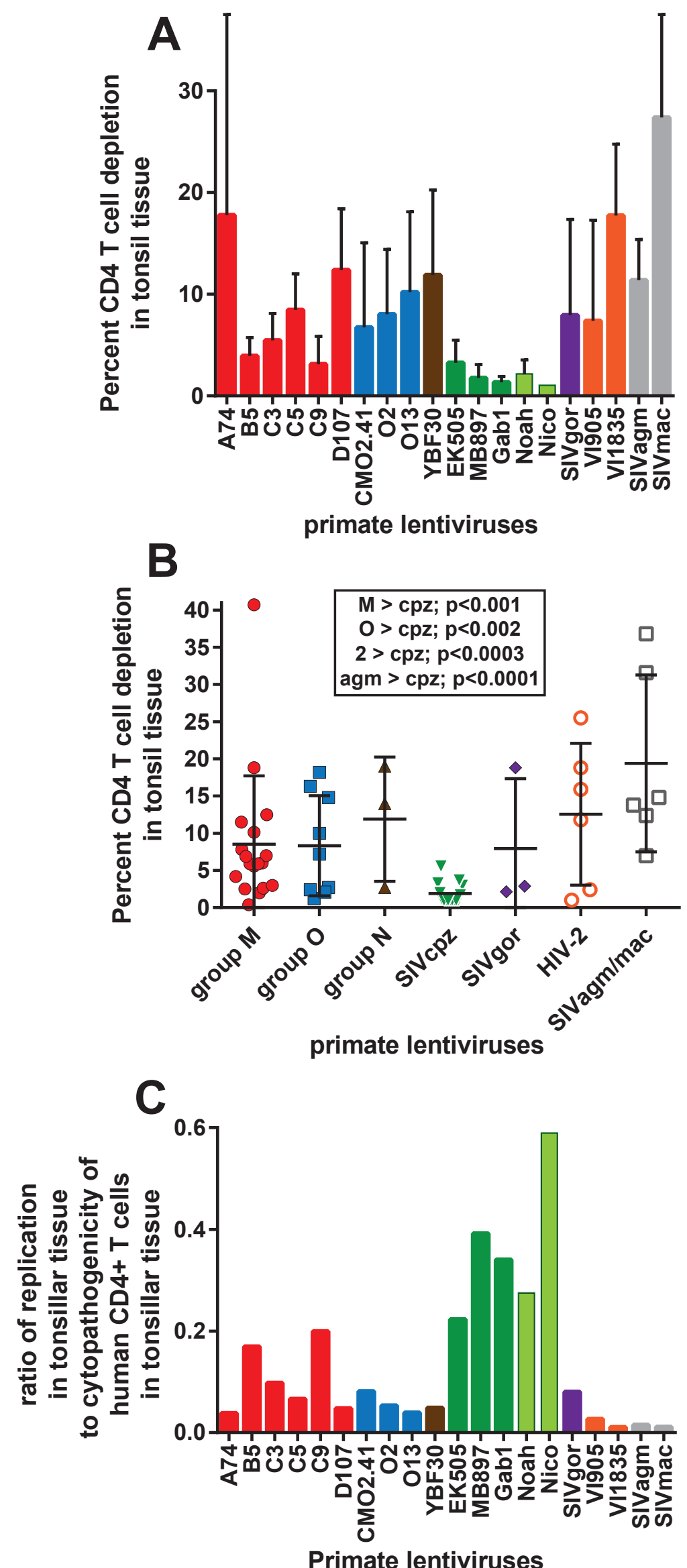

Figure 8: Primate lentiviral replication in tonsillar tissue and huPBMC fitness (A) Percentage of T-cell depletion; (B) CD4 T-cell depletion levels within a group or type of primate lentivirus; (C) Comparing the replication in tonsillar tissue to cytopathogenicity 


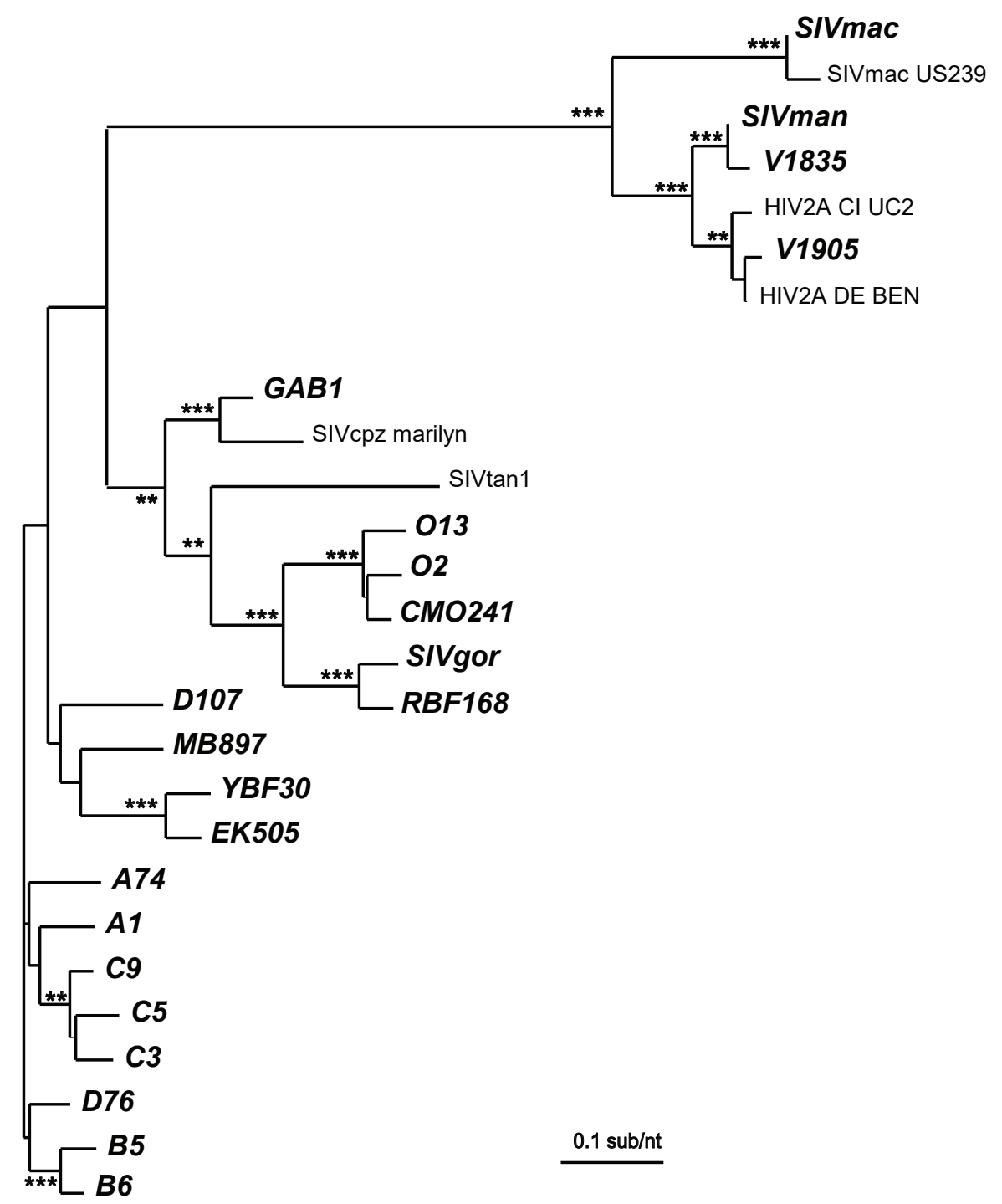

Supplementary Figure 1: Neighbor joining phylogenetic tree of the gag p24 sequences of primate lentiviruses with reference strains. 


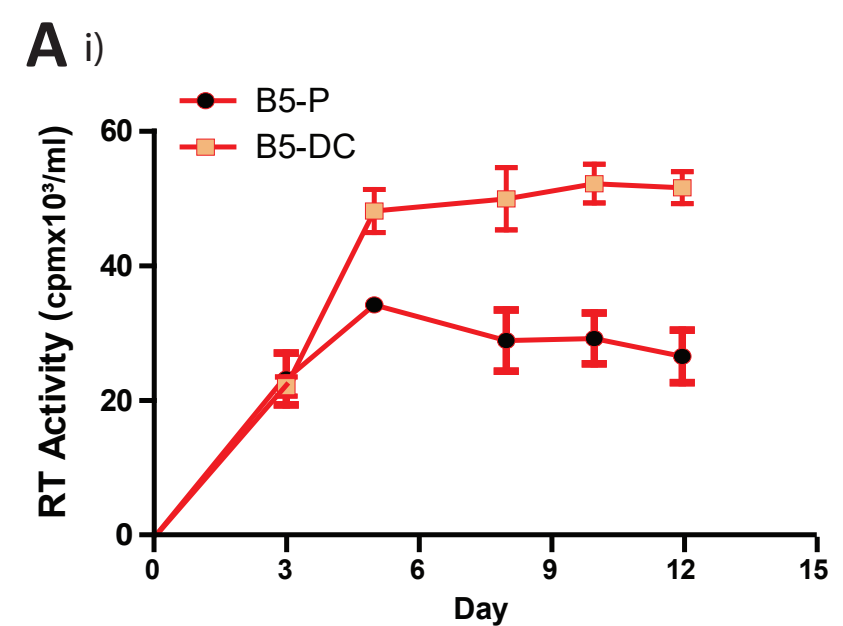

iii)

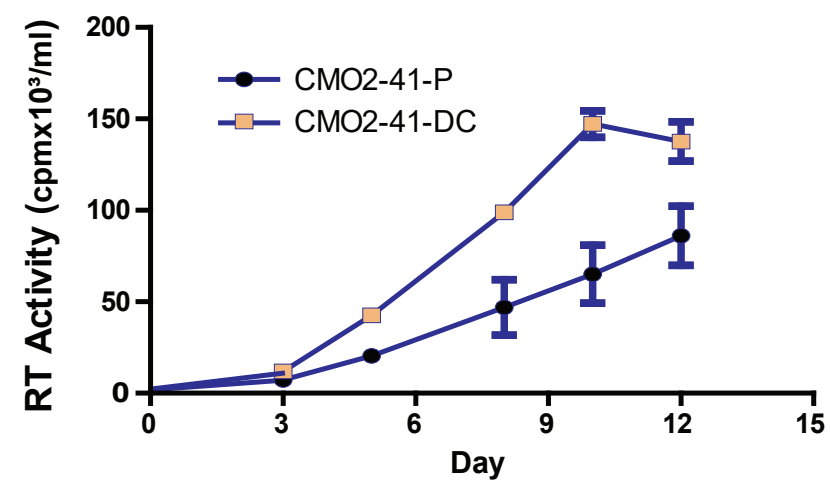

ii)

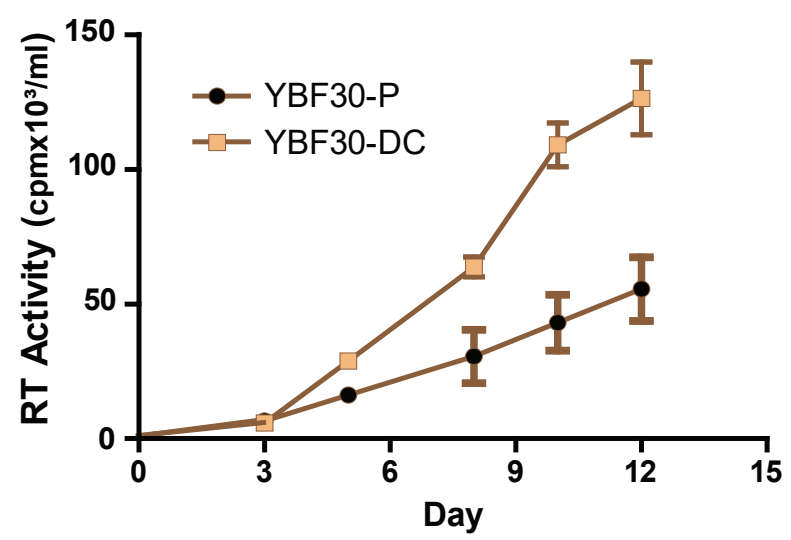

iv)

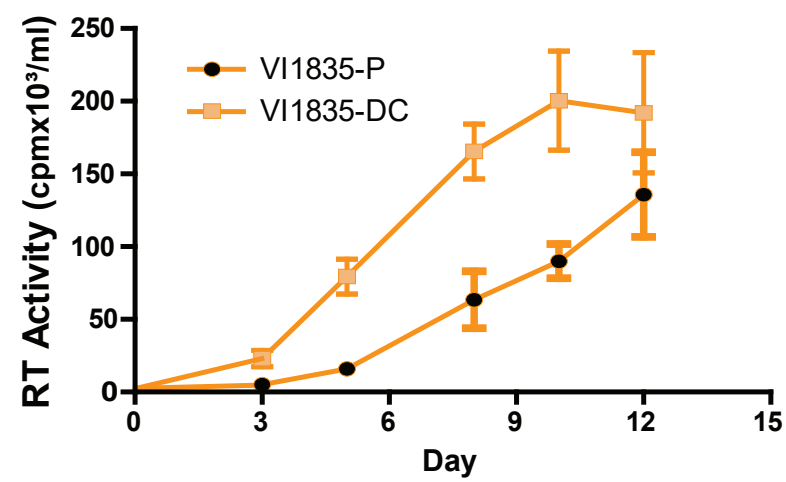

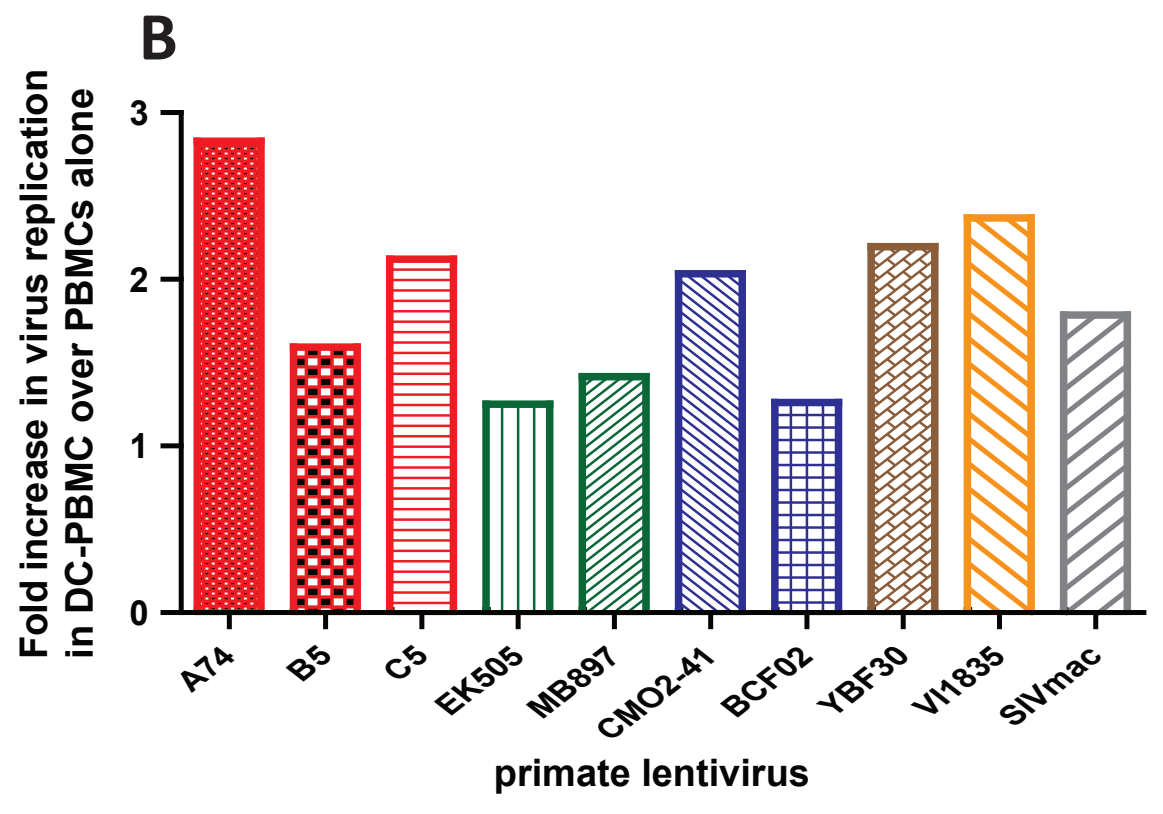

Supplementary Figure 2: Enhancement of HIV and SIV replication in PBMC+dendritic cell cultures. A) Comparison of the replication kinetics of some isolates in PBMC (P, black filled circles) and PBMC+DC (DC, gold filled squares) co-cultures. B) Fold difference showing enhancement in replication by DCs. 
bioRxiv preprint doi: https://doi.org/10.1101/2020.10.13.337303; this version posted October 13,2020 . The copyright holder for this preprint (which was not certified by peer review) is the author/funder, who has granted bioRxiv a license to display the preprint in perpetuity. It is made available under aCC-BY 4.0 International license.
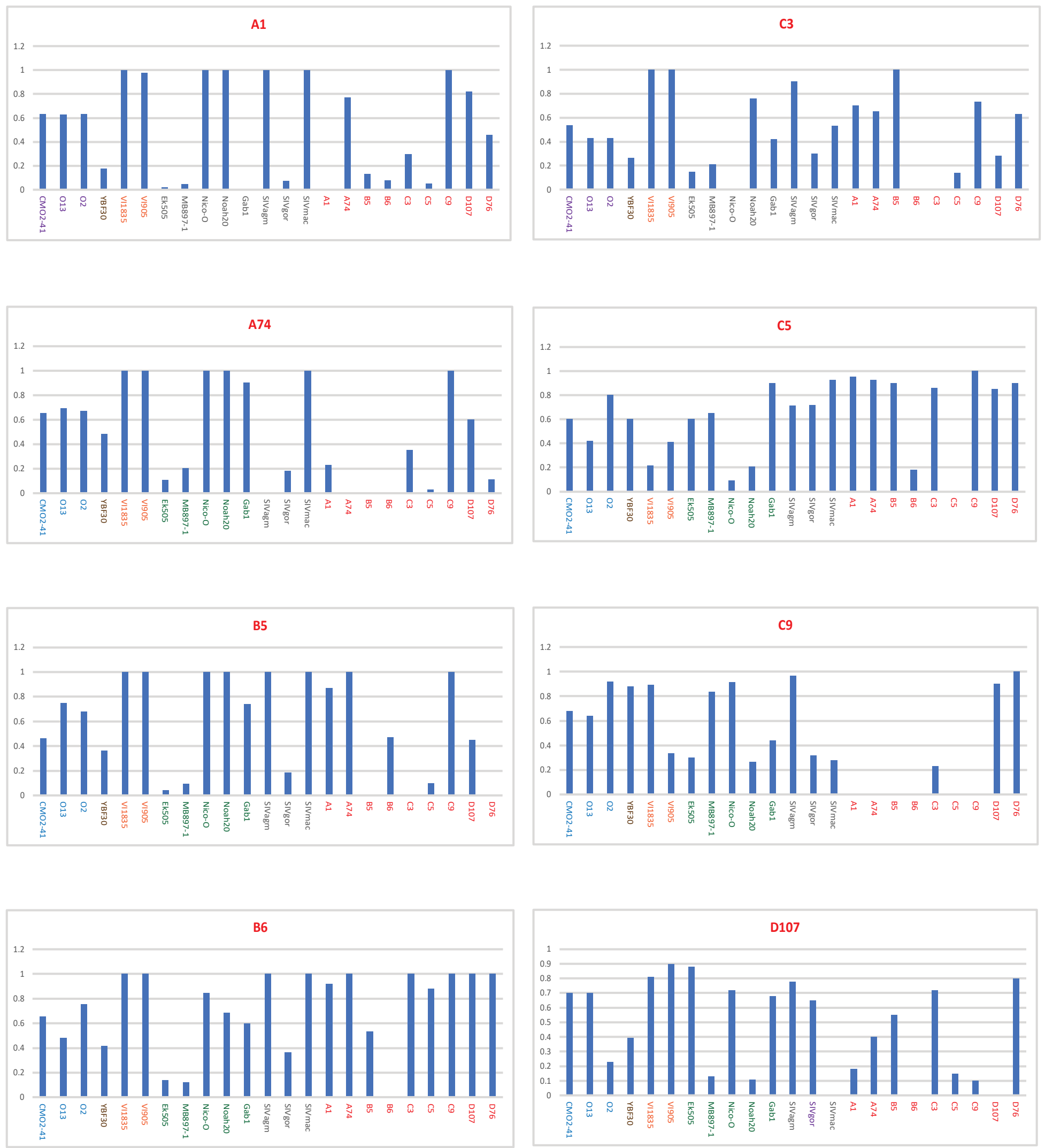

Supplementary Figure 3a: Fitness of primate lentiviruses in human PBMC. Primate lentivirus were added to HsPBMCs for a full pairwise competition. Production of the "titled" virus in each chart is presented as fraction of the total when competed against the virus on the $X$ axis. Relative virus production was measured from PCR and deep sequencing analyses using the SeekDeep pipeline. All competitions were performed in duplicate with a $10 \%$ observed variance in fitness. 
bioRxiv preprint doi: https://doi.org/10.1101/2020.10.13.337303; this version posted October 13, 2020. The copyright holder for this preprint (which was not certified by peer review) is the author/funder, who has granted bioRxiv a license to display the preprint in perpetuity. It is made available under aCC-BY 4.0 International license.
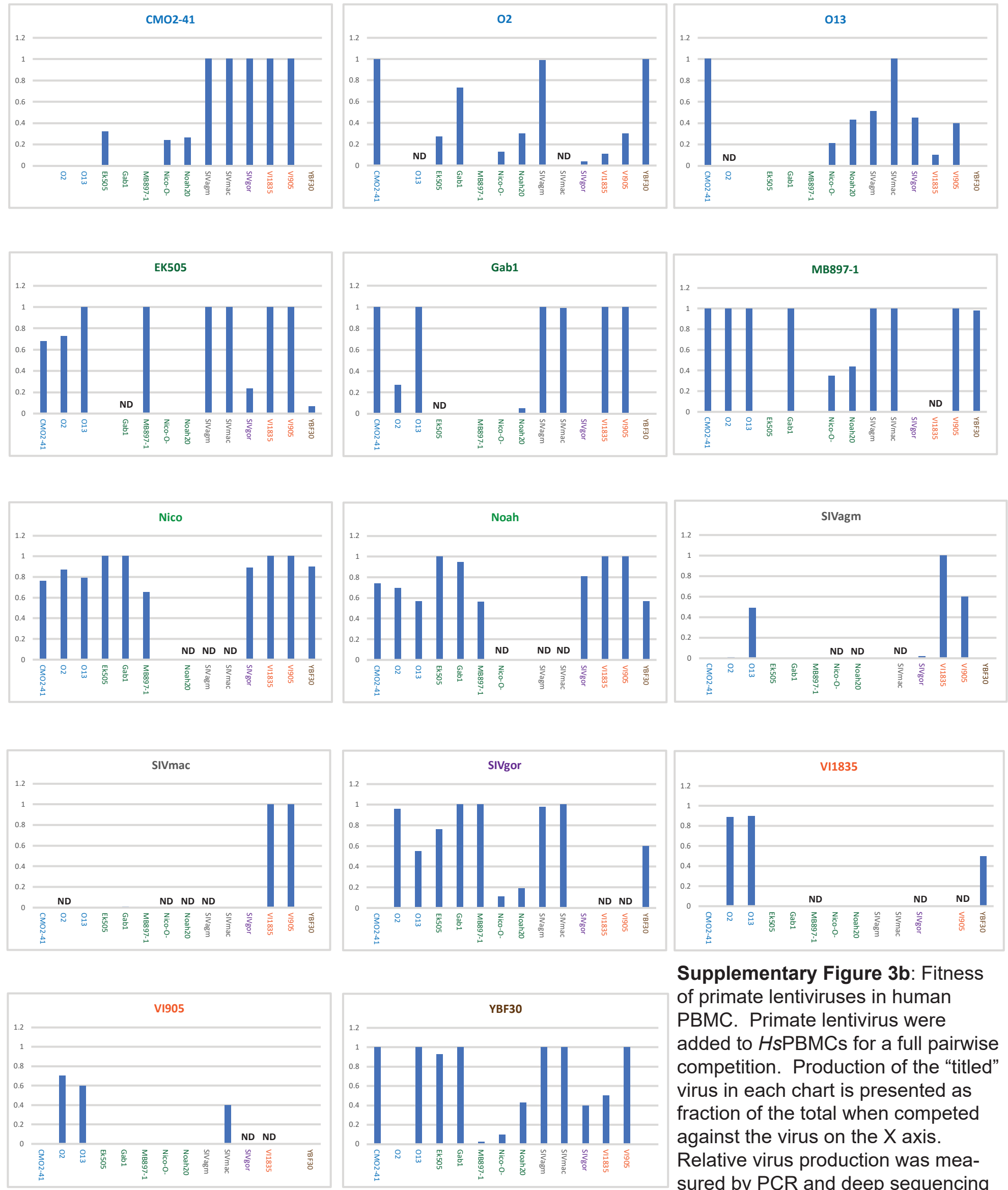

Supplementary Figure 3b: Fitness of primate lentiviruses in human PBMC. Primate lentivirus were added to HsPBMCs for a full pairwise competition. Production of the "titled" virus in each chart is presented as fraction of the total when competed against the virus on the $X$ axis.

Relative virus production was measured by PCR and deep sequencing analyses using the SeekDeep pipeline. All competitions were performed in duplicate with a $10 \%$ observed variance in fitness. 
bioRxiv preprint doi: https://doi.org/10.1101/2020.10.13.337303; this version posted October 13, 2020. The copyright holder for this preprint (which was not certified by peer review) is the author/funder, who has granted bioRxiv a license to display the preprint in perpetuity. It is made available under aCC-BY 4.0 International license.

A1

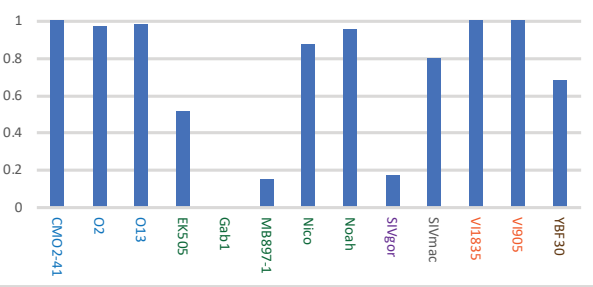

CMO2-41

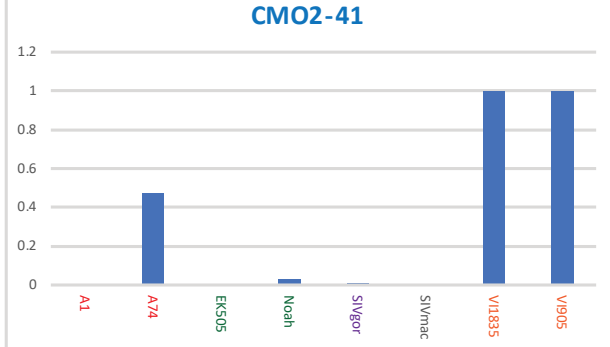

EK505

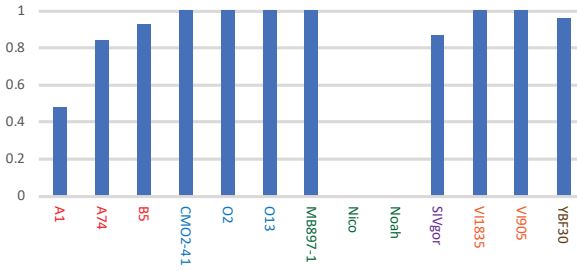

Nico-O

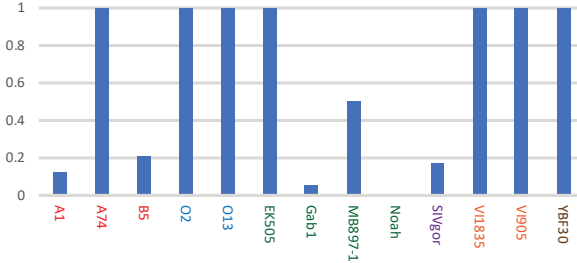

SIVmac

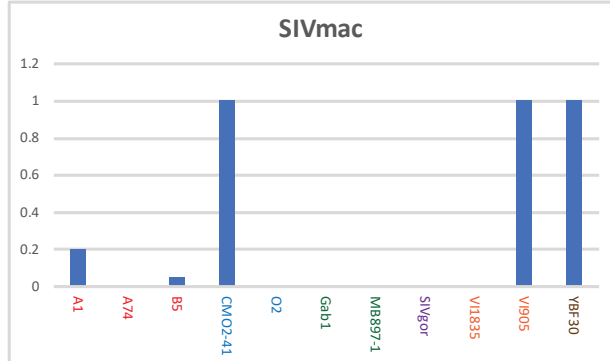

A74

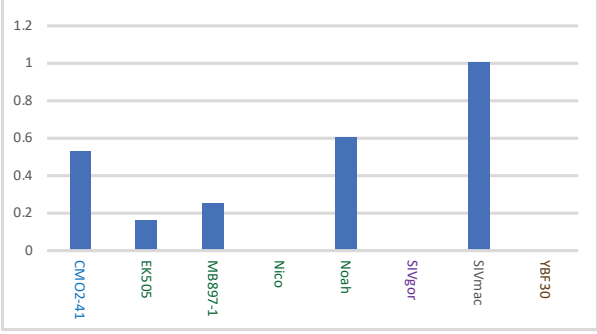

02

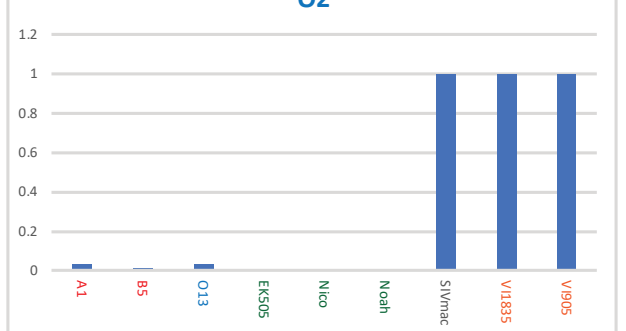

Gab1

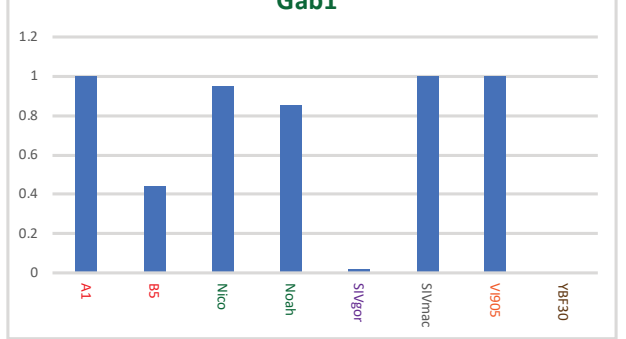

Noah20

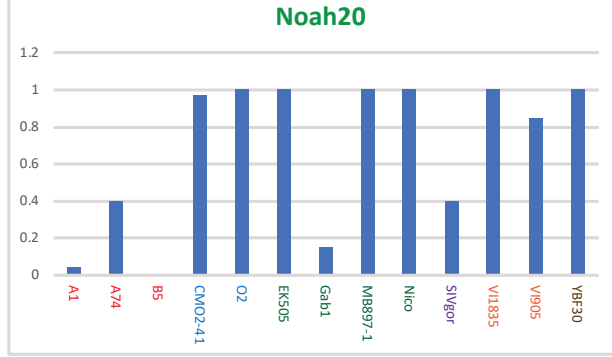

VI1835

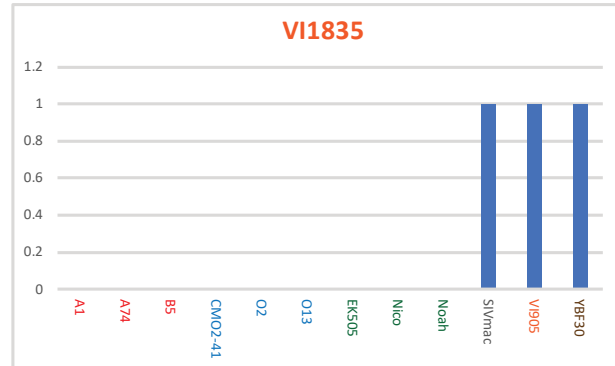

Supplementary Figure 3c: Fitness of primate lentiviruses in chimp PBMC. Primate lentivirus were added to PtvPBMCs for a partial pairwise competition. Production of the "titled" virus in each chart is presented as fraction of the total when competed against the virus on the $X$ axis. Relative virus production was measured from PCR and deep sequencing analyses using the SeekDeep pipeline. All competitions were performed in duplicate with a $10 \%$ observed variance in fitness.

B5

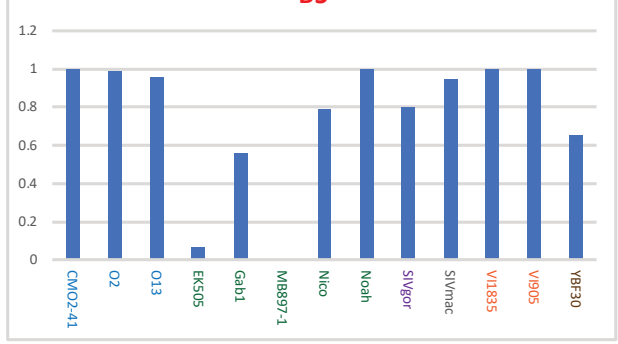

013

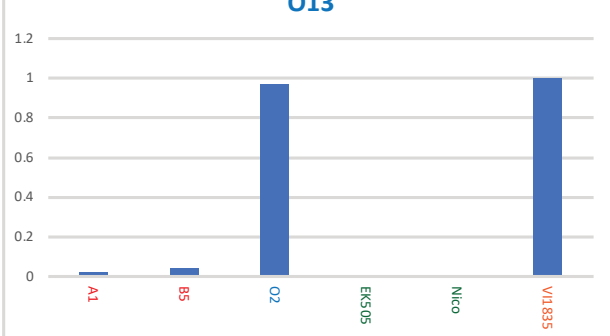

MB897

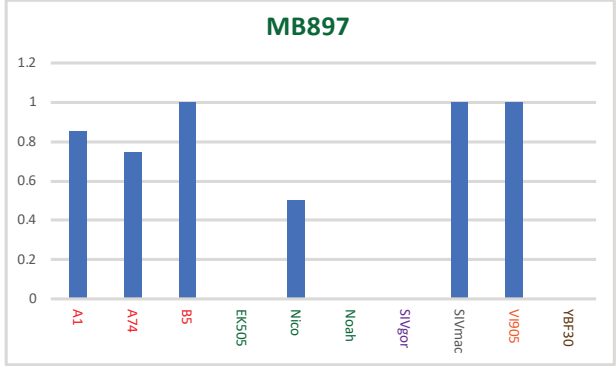

SIVgor

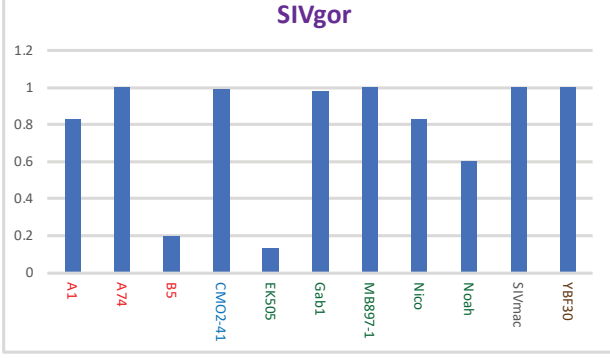

VI905

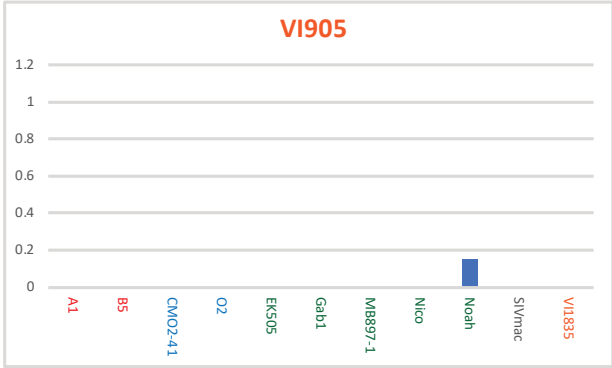

YBF30

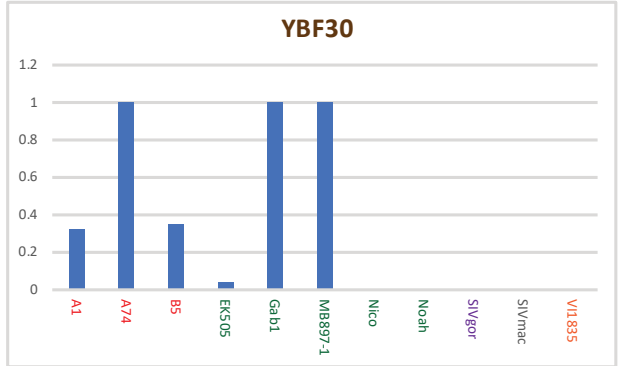


bioRxiv preprint doi: https://doi.org/10.1101/2020.10.13.337303; this version posted October 13, 2020. The copyright holder for this preprint (which was not certified by peer review) is the author/funder, who has granted bioRxiv a license to display the preprint in perpetuity. It is made available under aCC-BY 4.0 International license.
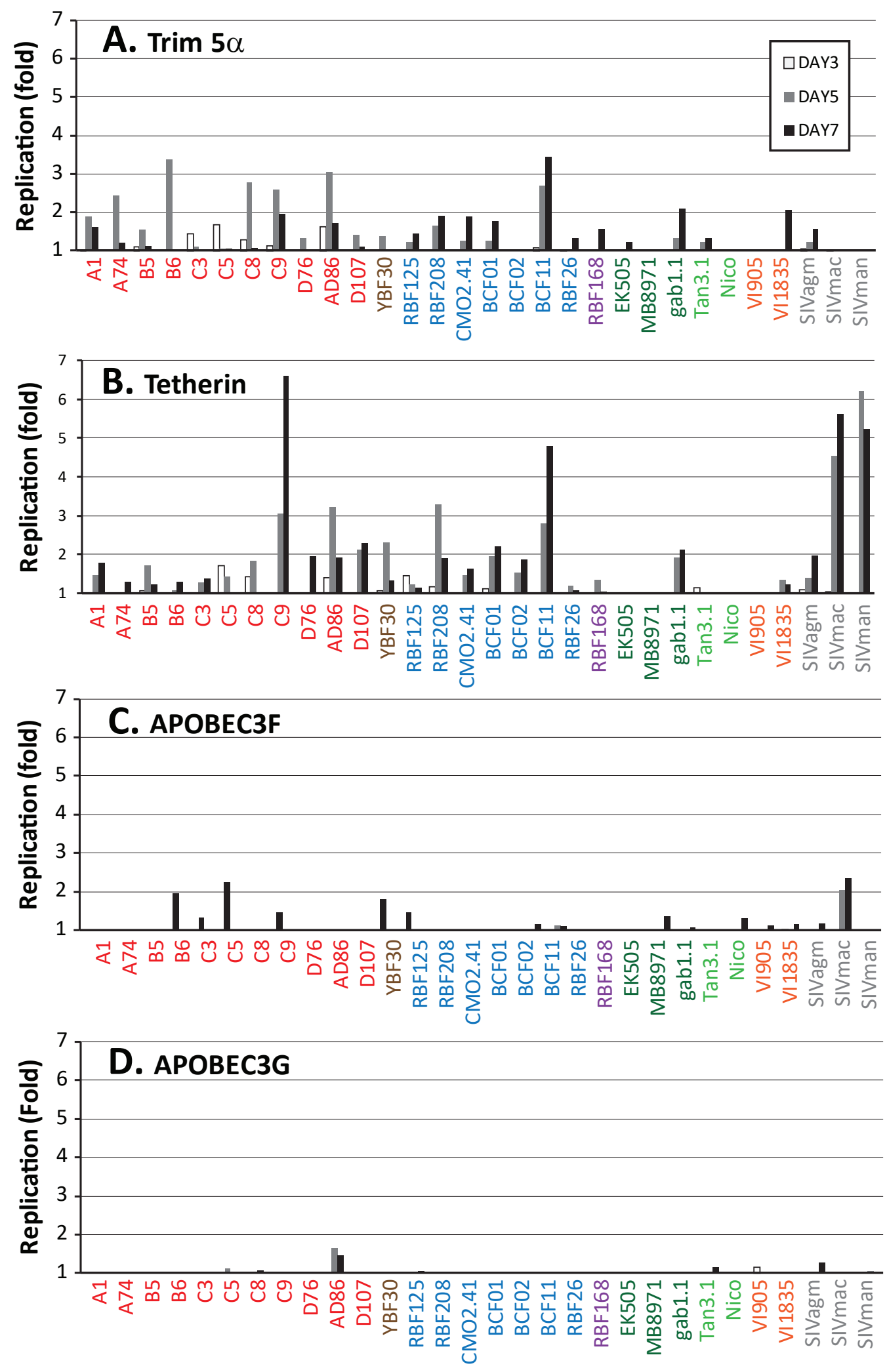

Virus

Supplementary Figure 4. Primate lentivirus replication in human CD4+ U87 cells expressing HsCCR5 and pre-treated with siRNA to human restiriction factors Trim 5a (A), Tetherin/BST2 (B), APOBEC3F (C), and APOBEC3G (D). Replication is plotted as the fold change in increased lentivirus replication on days 3,5 , and 7 in the presence of siRNA to specific human restriction factors. 


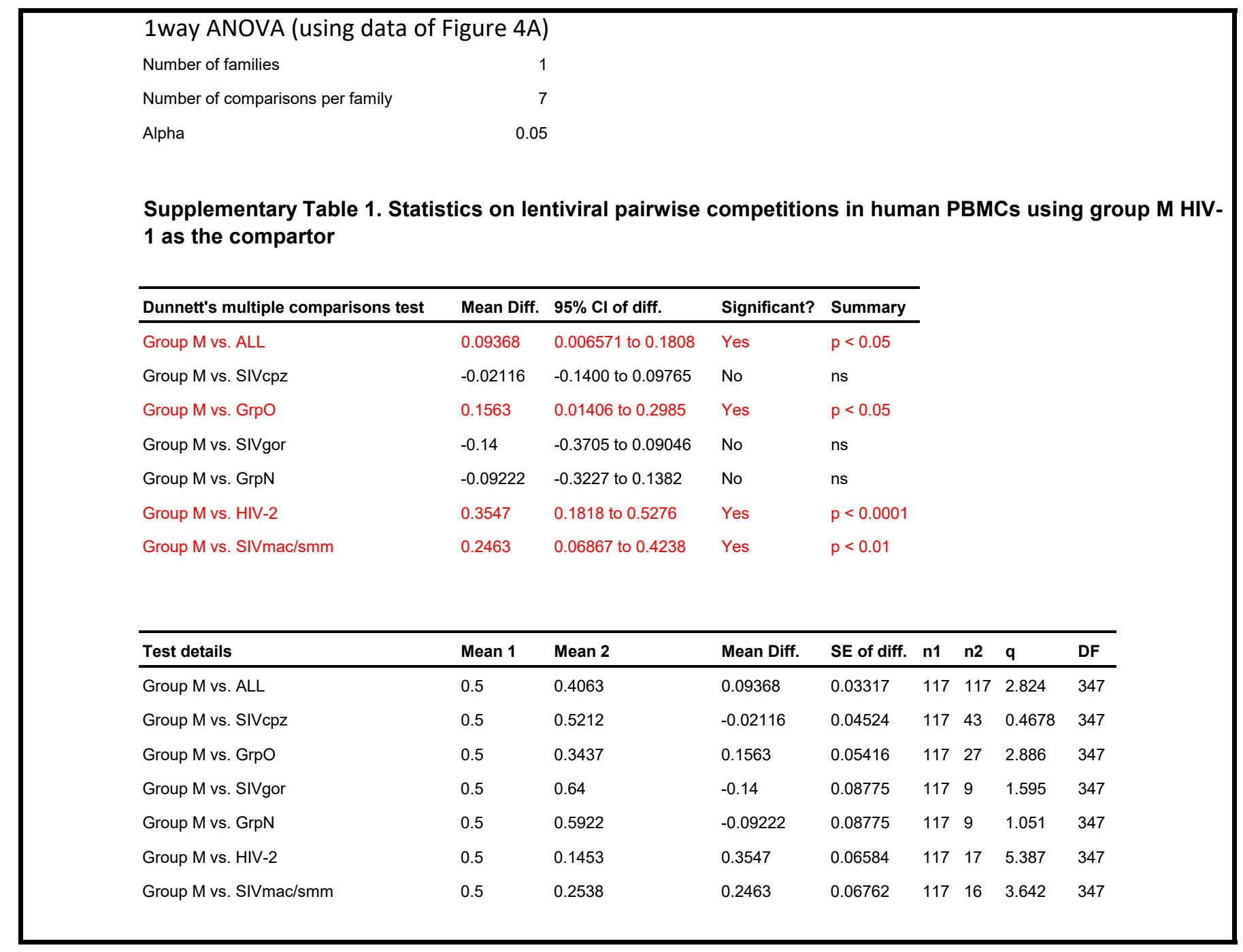




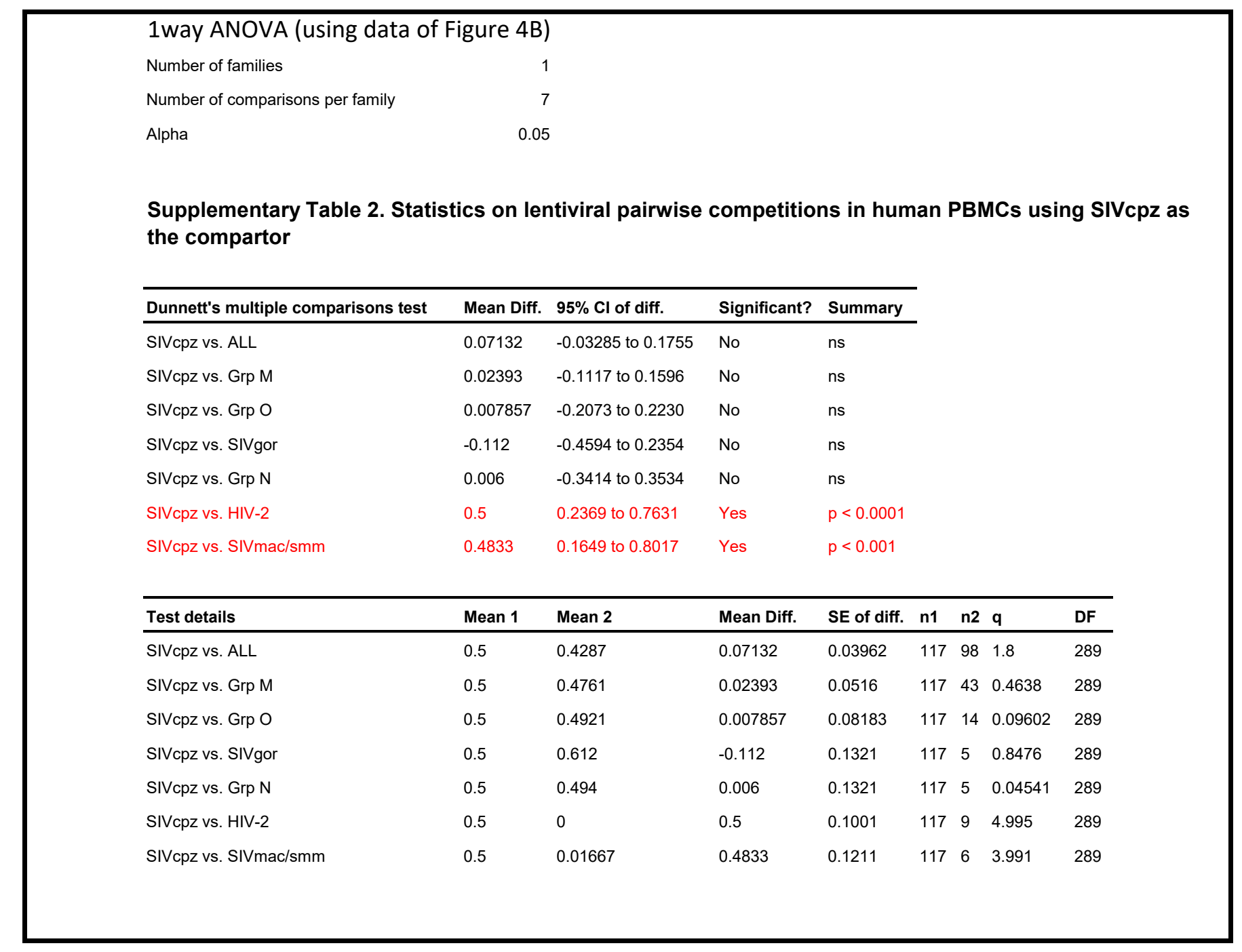




\begin{tabular}{|c|c|c|c|c|c|c|c|c|c|c|c|}
\hline \multicolumn{12}{|c|}{ 1way ANOVA (using data of Figure 4C) } \\
\hline \multicolumn{2}{|l|}{ Number of families } & \multicolumn{10}{|l|}{1} \\
\hline Number of comparisons per family & & \\
\hline \multicolumn{12}{|l|}{ Alpha } \\
\hline \multicolumn{12}{|c|}{$\begin{array}{l}\text { Supplementary Table } 3 \text {. Statistics on lentiviral pairwise competitions in chimp PBMCs using HIV-1 M as } \\
\text { the compartor }\end{array}$} \\
\hline Dunnett's multiple comparisons test & Mean D & & \multicolumn{2}{|c|}{ Significant? } & \multicolumn{2}{|l|}{ Summary } & & & & \\
\hline Group M vs. ALL & 0.11390 .008974 to 0.2189 & & & \multicolumn{2}{|c|}{ Yes } & \multicolumn{2}{|l|}{$p<0.05$} & & & & \\
\hline Group M vs. SIVcpz & \multicolumn{3}{|c|}{$-0.08714-0.2377$ to 0.06346} & \multicolumn{2}{|l|}{ No } & \multicolumn{2}{|c|}{ ns } & & & & \\
\hline Group M vs. Grp O & \multicolumn{3}{|c|}{0.4050 .1821 to 0.6279} & Yes & & \multicolumn{3}{|l|}{$p<0.0001$} & & & \\
\hline Group M vs. SIVgor & \multicolumn{3}{|c|}{$-0.1767-0.4880$ to 0.1347} & No & & \multicolumn{2}{|c|}{ ns } & & & & \\
\hline Group M vs. Grp N & \multicolumn{3}{|c|}{$0.2433-0.06804$ to 0.5547} & No & & \multicolumn{2}{|c|}{ ns } & & & & \\
\hline Group M vs. HIV-2 & \multicolumn{3}{|c|}{0.50 .3054 to 0.6946} & Yes & & \multicolumn{2}{|l|}{$p<0.0001$} & & & & \\
\hline Group M vs. SIVmac/man & \multicolumn{3}{|c|}{0.41670 .1053 to 0.7280} & Yes & & \multicolumn{2}{|l|}{$p<0.01$} & & & & \\
\hline Test details & Mean 1 & Mean 2 & & & an Diff. $\quad s$ & SE of diff. & n1 & $\mathrm{n} 2$ & $q$ & $\mathrm{DF}$ & \\
\hline Group M vs. ALL & & .5 & 0.3861 & & 0.1139 & 0.03978 & 117 & 33 & 2.864 & $\overline{179}$ & \\
\hline Group M vs. SIVcpz & & .5 & 0.5871 & & -0.08714 & 0.05707 & 117 & 14 & 1.527 & 179 & \\
\hline Group M vs. Grp O & & .5 & 0.095 & & 0.405 & 0.08448 & 117 & 6 & 4.794 & 179 & \\
\hline Group M vs. SIVgor & & .5 & 0.6767 & & -0.1767 & 0.118 & 117 & 3 & 1.497 & 179 & \\
\hline Group M vs. Grp N & & .5 & 0.2567 & & 0.2433 & 0.118 & 117 & 3 & 2.062 & 179 & \\
\hline Group M vs. HIV-2 & & .5 & 0 & 0 & 0.5 & 0.07375 & 117 & 8 & 6.779 & 179 & \\
\hline Group M vs. SIVmac/man & & .5 & 0.08333 & & 0.4167 & 0.118 & 117 & 3 & 3.531 & 179 & \\
\hline
\end{tabular}




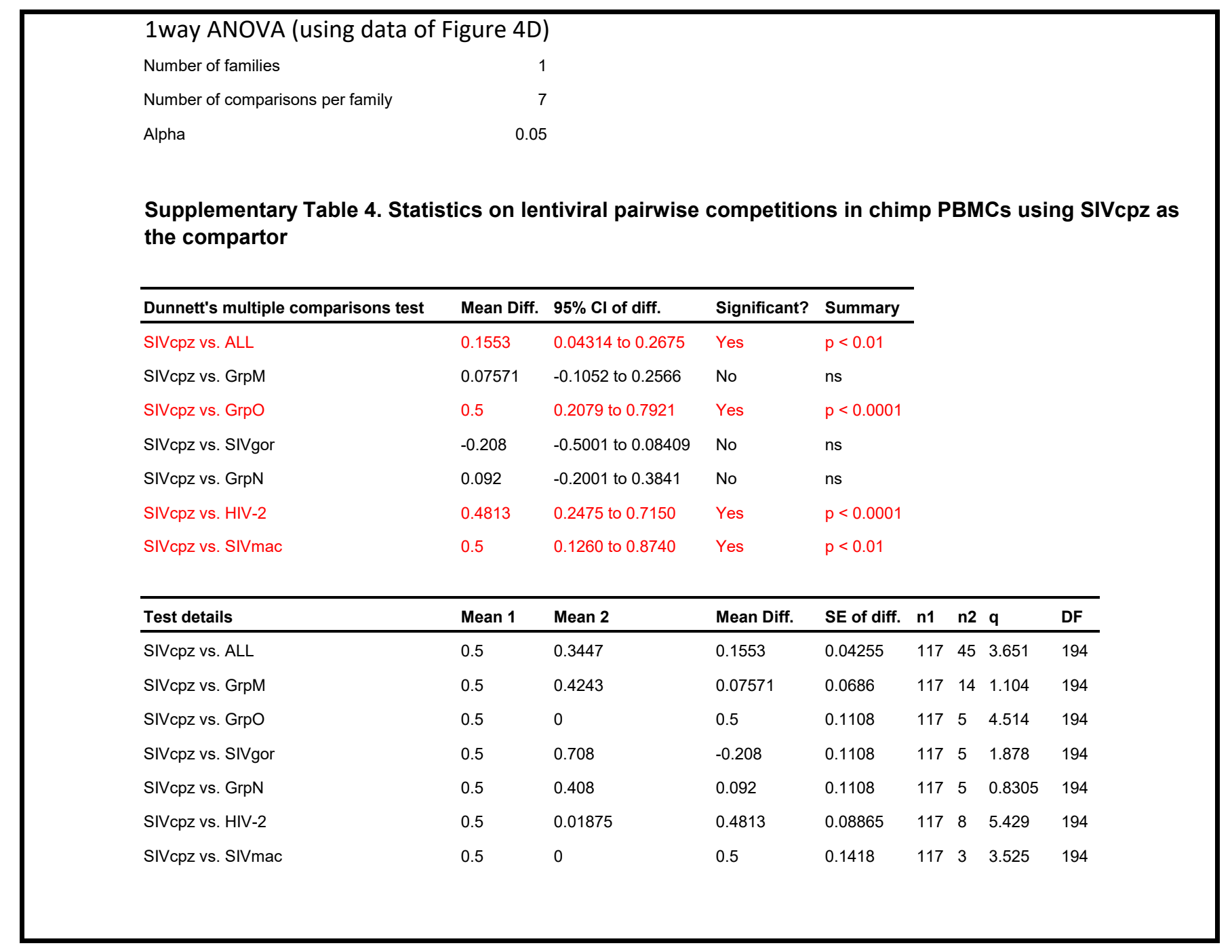




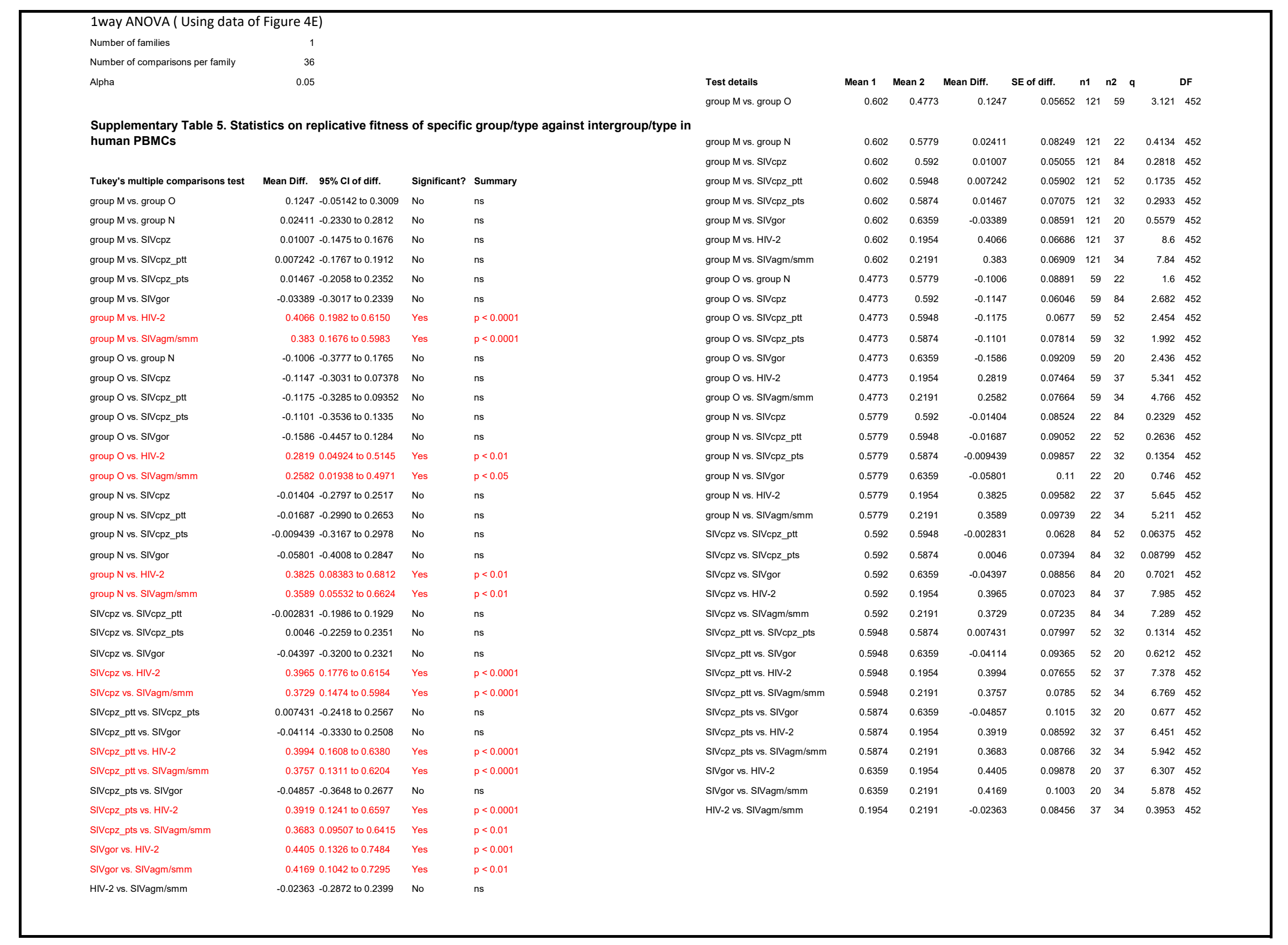


1way ANOVA (using data of Figure 5A)

Number of families

Number of comparisons per family

Alpha

1

Supplementary Table 6. Statistics on SIVcpz_Ptt and SIVcpz_Pts pairwise competitions in human PBMCs using HIV-1 M as the compartor

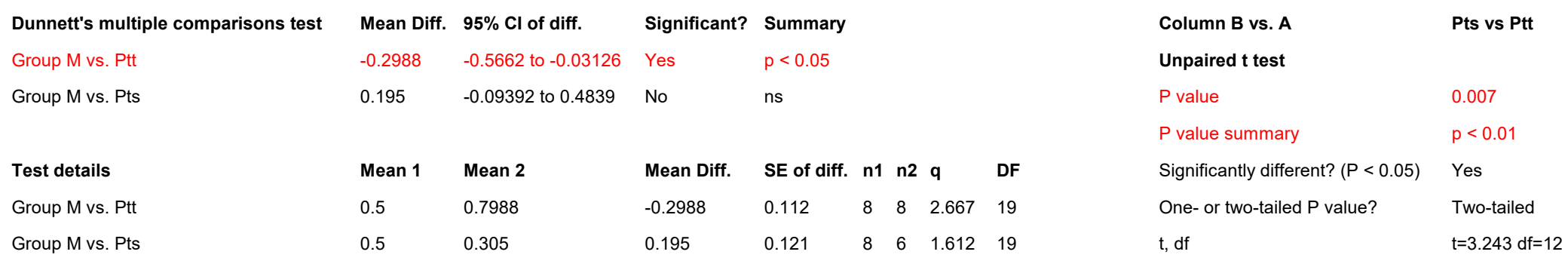

1way ANOVA (using data of Figure 5B)

Number of families

Number of comparisons per family

Alpha

1
2
05

Supplementary Table 7. Statistics on SIVcpz_Ptt and SIVcpz_Pts pairwise competitions in chimp PBMCs using HIV-1 M as the compartor

\begin{tabular}{|c|c|c|c|c|c|}
\hline Dunnett's multiple comparisons test & Mean Diff. & $95 \% \mathrm{Cl}$ of diff. & Significant? & Summary & \\
\hline Group M vs. Ptt & -0.1277 & -0.2817 to 0.02628 & No & ns & \\
\hline Group M vs. Pts & 0.1418 & -0.03325 to 0.3168 & No & ns & \\
\hline Test details & Mean 1 & Mean 2 & Mean Diff. & SE of diff. $n 1 \quad n 2 q$ & DF \\
\hline Group M vs. Ptt & 0.5 & 0.6277 & -0.1277 & $\begin{array}{llll}0.06824 & 32 & 26 & 1.871\end{array}$ & 72 \\
\hline Group M vs. Pts & 0.5 & 0.3582 & 0.1418 & $\begin{array}{llll}0.07757 & 32 & 17 & 1.828\end{array}$ & 72 \\
\hline
\end{tabular}

$\begin{array}{ll}\text { Column B vs. A } & \text { Pts vs Ptt } \\ \text { Unpaired t test } & \\ \text { P value } & 0.0156 \\ \text { P value summary } & \mathrm{p}<0.05 \\ \text { Significantly different? }(\mathrm{P}<0.05) & \text { Yes } \\ \text { One- or two-tailed } \mathrm{P} \text { value? } & \text { Two-tailed } \\ \mathrm{t}, \mathrm{df} & \mathrm{t}=2.522 \mathrm{df}=41\end{array}$

